\title{
Performance Evaluation of design and operational parameters of Conventional Combine Harvester for Basmati Rice (Oryza Sativa)
}

Manvendra Bhardwaj

Punjab Agricultural University

Ritu Dogra ( $\sim$ ritudogra@pau.edu )

Punjab Agricultural University https://orcid.org/0000-0002-2675-4121

Mohammed Javed

Punjab Agricultural University

Manjeet Singh

Punjab Agricultural University

Baldev Dogra

Punjab Agricultural University

Original article

Keywords: Conventional combine harvester, Basmati rice

Posted Date: June 24th, 2020

DOI: https://doi.org/10.21203/rs.3.rs-36945/v1

License: (c) (1) This work is licensed under a Creative Commons Attribution 4.0 International License.

Read Full License 


\section{Abstract}

Among all the food grains, Basmati rice (Oryza sativa) has significant export potential. At present, majority of harvesting and threshing of basmati is accomplished manually because of high quality of grain. Manual harvesting and threshing operation is quite costly and mostly done by hired labour, threshing cost and family labour. Labour in harvesting has become scarce due to industrialization. The commercially available machines for paddy harvesting and threshing are not suitable for basmati varieties because of relatively delicate nature. There is no data available regarding design and operational parameters for harvesting basmati with conventional combine harvester. Therefore, this study has been planned to study the effect of selected design and operational parameters of threshing mechanism of conventional combine harvester for basmati crop and to compare the performance with prevalent practice. Field evaluation of experiment was carried out to assess the influence of independent design variable i.e., arrangement of spikes (AS) and independent operational parameters namely concave clearance (CC) and cylinder speed (CS). The study was aimed to quantify various combining losses viz., extent of grain damage (visible and invisible), unthreshed and clean grain losses in straw walker at different arrangement of spikes, concave clearance and cylinder speed. Initial testing of conventional combine harvester on PUSA Basmati-1121 to reduce the visible as well invisible losses had been carried out at PAU Regional Research Station, Gurdaspur (Punjab) during the year 2017.

\section{Highlights}

(1) Arrangement of spikes 44, 68 and 136 spikes were investigated and found that 44 spikes gives minimized losses in terms of grain loss (visible and invisible loss).

(2) Concave clearance 13-9, 15-11 and 17-13 mm were investigated and found that 17-13 $\mathrm{mm}$ gives minimized losses in terms of grain loss (visible and invisible loss).

(3) Cylinder speed 560, 640 and $720 \mathrm{rpm}$ were investigated and found that $560 \mathrm{rpm}$ gives minimized losses in terms of grain loss (visible and invisible loss).

(4) AS1CC3CS1 (44 spikes, 17-13 mm and $560 \mathrm{rpm}, 2017$ ) was better combination as it minimized the visible loss to $3.50 \%$, it also minimized the invisible loss to $17.33 \%$.

(5) Optimum values obtained through optimization at this combination of AS1CC3CS1 where visible loss was $3.42 \%$, invisible loss was $18 \%$ and threshing efficiency was $98.706 \%$ for the year 2017 .

\section{Background}

Paddy is the major crop of Punjab and Basmati rice has a special status in rice cultivation. It is known for excellent cooking and eating qualities. Basmati varieties occupy about 20 percent rice area in Punjab. At present, majority of harvesting and threshing of basmati is accomplished manually because of high quality of grain. Manual harvesting of basmati is a labour intensive operation requiring about 
approximately $180 \mathrm{man}-\mathrm{h} / \mathrm{ha}$. Some times during the peak periods of harvesting and threshing, nonavailability of labour delays the operation of harvesting. Another option is axial flow combines however, the cost of axial attachment may deter combine operators. There is no data available regarding design and operational parameters for harvesting basmati with conventional combines. Therefore, this study has been planned to find suitable changes required in conventional combine harvester for harvesting basmati rice. The study was aimed to enumerate various combining losses viz., extent of grain damage (visible and invisible), un-threshed and clean grain losses in straw outlet at different arrangement of spikes, concave clearance and cylinder speed. The various parameters selected were arrangement of spikes viz., 44, 68 and 136 spikes; concave clearance viz., $13 \mathrm{~mm}$ at entry and $9 \mathrm{~mm}$ at rear, $15 \mathrm{~mm}$ at entry and $11 \mathrm{~mm}$ at rear and $17 \mathrm{~mm}$ at entry and $13 \mathrm{~mm}$ at rear and cylinder speed viz., 560, 640 and $720 \mathrm{rpm}$ (2017). The data has been analyzed by statistical software SPSS software and optimization has been done by optimization technique i.e., Design Expert 11. Arrangement of spikes 44, 68 and 136 spikes were investigated and found that 44 spikes gives minimized losses in terms of grain loss (visible and invisible loss). Concave clearance 13-9,15-11 and 17-13 mm were investigated and found that $17-$ $13 \mathrm{~mm}$ gives minimized losses in terms of grain loss (visible and invisible loss). Cylinder speed 560, 640 and $720 \mathrm{rpm}$ were investigated and found that $560 \mathrm{rpm}$ gives minimized losses in terms of grain loss (visible and invisible loss). AS1CC3CS1 (44 spikes, $17-13 \mathrm{~mm}$ and $560 \mathrm{rpm}, 2017$ ) was better combination as it minimized the visible loss to $3.50 \%$, it also minimized the invisible loss to $17.33 \%$. Optimum values obtained through optimization at this combination of AS1CC3CS1 where visible loss was $3.42 \%$, invisible loss was $18 \%$ and threshing efficiency was $98.706 \%$.

\section{Introduction}

Paddy is the major crop of Punjab and Basmati rice has a special status in rice cultivation. It is known for excellent cooking and eating qualities. Basmati varieties occupy about 20 percent rice area in Punjab. The average yield of basmati was $4500 \mathrm{~kg} / \mathrm{ha}$ (Anonymous 2018-19). The time of sowing basmati is 1530 June. Seedlings of basmati are ready for transplanting after 25 to 30 days. Ground water depletion decreases with the arrival of monsoon in the month of July, so it is beneficial to sow basmati crop. There is always an option of going for the wheat-basmati rice rotation. Basmati should be harvested as soon as it matures. Delayed harvesting will cause over- ripening and shattering of grains (Anonymous 2015). In Punjab, the total basmati area was 7,63,000 ha (Anonymous 2018-19). The production of PUSA Basmati1121 is maximum i.e., 20.47 million metric tonnes. Basmati is an important export commodity among the food grains exported from India. During the past few years, basmati export has been growing steadily from 0.771 million metric tonnes in 2003 to an estimated 4.41 million metric tonnes in 2018-19. India's exports will be 5 to 6 million metric tonnes by 2020. Almost 132 countries have been importing basmati from India every year. Iran and Saudi Arabia are leading destinations, accounting 50-55\% of Basmati rice exports from India (Anonymous 2018-19).

Harvesting and threshing of paddy has been done in three ways, namely manual harvesting and threshing; manual harvesting and threshing with thresher; and harvesting with combine. There are mainly three forces acting on a plant while reaping the plant for cutting. These forces are impact of reel, couple 
of cutting resistance and impact as forces and weight of the ear and its forced acceleration multiplied by the mass component on the opposite to the forced direction (Biggs and Stewart 1954). Lamp and Bushele (1960) defined threshing as the process of freeing the seed from its attachment and this occurs whenever the applied forces on kernels exceed the sum of forces restraining it on the ear-head. Four general methods for obtaining the threshing force namely mechanical rubbing, impact or impulsive threshing, mechanical stripping and non-impulsive threshing were enumerated. Action of drum in threshing was explained by Whitney et al (1966). At the very beginning of feeding the straw, the drum beats down the ears with its teeth. The drum then grips the straw and while pulling it through the packer compresses the ears together with straw, separating the grain from them and finally the drum ejects the straw.

Main advantage of combine harvester is that it can harvest and thresh the crop in a single operation. Thus, combines have helped in timely harvesting and threshing. Combine harvesting saves time, labour and cost apart from weather risks. However, major problem in combine- harvested basmati crop is higher percentage of fissured grain as gain is long leading to reduced rice recovery during milling. Most of the combine harvesters currently used in India employ rasp-bar or spike-tooth type tangential threshing drums and straw walker. This conventional tangential threshing unit threshes mostly by impact (Kutzbach and Quick 1999).

Traditional combines have very less cylinder to concave clearance (around $25 \mathrm{~mm}$ at inlet and $10 \mathrm{~mm}$ at concave outlet). Particularly in spike tooth type threshing cylinders having counter spikes, it is further reduced to $7 \mathrm{~mm}$ (Singh 1999). This in turn results in aggressive threshing action. This aggressive threshing action leads to higher percentage of visible and invisible grain damage particularly in paddy. The invisible grain damage caused during threshing gets reflected as reduced recovery of whole grain during milling operation.

At present, majority of harvesting and threshing of basmati is accomplished manually because of high quality of grain. Manual harvesting of basmati is a labour intensive operation requiring about approximately $180 \mathrm{man}-\mathrm{h} / \mathrm{ha}$. Some times during the peak periods of harvesting and threshing, nonavailability of labour delays the operation of harvesting which causes progressive decrease in yield of next crop i.e., wheat due to late sowing (Garg and Madan 1989). Manual harvesting and threshing operation is also quite costly and mostly done by hired labour, threshing cost and family labour which generally costs about Rs. 4704 per hectare (Ahuja et al 2007). Labour in harvesting has become scarce due to industrialization. Commercially available machines for paddy harvesting and threshing are not suitable for basmati varieties because of relatively delicate nature (Sinha et al 2014).

Another option is axial flow combines, in which crop advances through the threshing mechanism in a direction parallel to the axis of rotor rather than perpendicular as in case of conventional threshing cylinder. The rotor threshes the grain by a combination of rubbing, impact and centrifugal action as the crop passes repeatedly. Generally, it takes more than three drum rotations in case of axial threshing system (i.e. 1080 degrees) before the crop is ejected out of the threshing cylinder as compared to 120 to 
150 degrees in tangential cylinder. The repeated passes in the threshing system in case of axial system provide more retention time but gentle threshing action. Since the retention time as well as cylinder to concave clearance are more in axial threshing drum in comparison to that in tangential threshing drums thus the threshing is less aggressive. Another major advantage of axial flow combines over conventional combines is in terms of separation loss (DePauw et al 1977). However, the cost of axial attachment may deter combine operators. On the other hand, operation in controlled conditions has resulted a nonsignificant difference in grain loss in case of commercially available machines. Moreover, there are machine constraints in case of axial flow combines, as they are not available for custom hiring.

\section{Materials And Methods}

\section{Location}

The experimental studies were carried out at PAU Regional Research Station, Gurdaspur (Punjab) during November-December, 2017.

\section{Crop}

PUSA Basmati- 1121 was used for the experimental studies and it matures in about 137 days after seeding. It yields on an average 13.7 quintals of paddy per acre. PUSA Basmati- 1121 is of short duration among other improved varieties with maximum productivity. Optimum sowing time of PUSA Basmati1121 is 15-30 June. Northern districts of Punjab i.e., Gurdaspur, Tarantaran, Amritsar and Fazilka have maximum area under PUSA Basmati- 1121 (Total basmati area in Punjab is 6,15,630 ha).

\section{Conventional combine harvester}

The self-propelled conventional combine harvester was used to study the effect of selected design and operational parameters of threshing mechanism of conventional combine harvester for basmati crop. Brief specifications of the machine are given in the Table-1. 
Table 1

Brief specifications of conventional combine harvester

\begin{tabular}{|ll|}
\hline Particular & Specification \\
\hline Chassis & $51^{\prime \prime}$ \\
\hline Rront wheel & $18-04-30$ \\
\hline Number of straw walkers & $9-00-16$ \\
Number of steps & 5 \\
\hline Weight & 8500 kg (approx.) \\
\hline Cutting capacity for & $3-4$ acre per hour \\
\hline Wheat & $2-3$ acre per hour \\
\hline Paddy & Length : $12060 \mathrm{~mm}$, \\
\hline Overall dimensions (Transport) & Width : $3200 \mathrm{~mm}$ and \\
& Height : $3700 \mathrm{~mm}$ \\
\hline Overall dimensions (Working) & Length : $8450 \mathrm{~mm}$, \\
& Width : $4700 \mathrm{~mm}$ and \\
\hline Effective cutting width & Height : $3700 \mathrm{~mm}$ \\
\hline
\end{tabular}

\section{Variables under study}

The variables under study have been presented under the sub headings as dependent variables and independent variable.

\section{Dependent variables}

The study was related to optimize the machine and crop parameters for mechanical harvesting of PUSA Basmati-1121. Therefore, visible grain damage, invisible grain damage and threshing efficiency was included in this study.

\section{Independent variables}

Different parameters that affect the performance of combine have been considered in the present study were arrangement of spikes, concave clearance and cylinder speed. 


\section{Range of independent variables}

Three levels of arrangement of spikes viz., AS1 (44 spikes), AS2 (68 spikes) and AS3 (136 spikes), three levels of concave clearance viz., CC1 (13 mm at entry and $9 \mathrm{~mm}$ at rear), CC2 (15 mm at entry and $11 \mathrm{~mm}$ at rear) and CC3 (17 mm at entry and $13 \mathrm{~mm}$ at rear) and three levels of cylinder speed CS1 (560 rpm), CS2 (640 rpm) and CS3 (720 rpm) were selected for the study. Spikes were arranged on the threshing drum in the form of helical arrangement. Cylinder speed was varied by changing the pulleys, measured by tachometer in rpm. Forward speed of $1.5 \mathrm{~km} / \mathrm{h}$ was maintained throughout the experiment. Different outlets for enumerating losses were cylinder outlet, tank outlet, header outlet, straw walker and sieve outlet.

\section{Equipment for collecting samples and enumerating losses}

Two cylindrical rollers were specially fabricated for collecting the sieve and straw walker losses. A $10 \mathrm{~m}$ long and $1.5 \mathrm{~m}$ wide cloth was rolled on the cylindrical rollers to collect the sample of $10 \mathrm{~m}$ length during the harvesting. The cylindrical rollers were attached to the combine in such a way that they freely move on their axis during the operation of harvesting. For the measurement of the invisible grain damage, internal cracks in grains were determined with the help of an illuminated purity board.

\section{Evaluation procedure}

Preliminary field evaluation of experimental prototype was carried out at Regional Research Station, Gurdaspur (Punjab). The conventional combine harvester was operated for harvesting PUSA Basmati1121 as shown in Fig. 1. Preliminary field testing of prototype could be operated at a forward speed of $1.5 \mathrm{~km} / \mathrm{h}$. Test setup was able to cover $20 \mathrm{~m}$ in one minute. A field more than $100 \mathrm{~m}$ long and $40 \mathrm{~m}$ wide was selected for evaluation of test setup. It was assumed that ten metre run is sufficient for turning of combine harvester.

Field evaluation of the experimental setup for the year 2017 was carried out using randomized block design. There were three treatments for basmati rice i.e., arrangement of spikes (AS), cylinder speed (CS) and concave clearance $(\mathrm{CC})$ and each treatment had three levels forming $27(3 \times 3 \times 3)$ treatment combinations in the complete experiment. Each treatment was replicated thrice to make total number of trial runs equal to $81(27 \times 3)$. Sequence of trial runs/ experiments was selected by condition randomization. Arrangement of spikes in the form of helix was major operation. After that different cylinder speed at different helical arrangement of spikes and concave clearance was studied. Then effect of concave clearance over different helical pattern of spikes and at different cylinder speed was observed. These different treatments were tried to figure out the visible loss, invisible loss and threshing efficiency respectively.

Three samples of grains approximately $250 \mathrm{~g}$ each were taken at each experimental setup. The losses were measured at variable cylinder speeds for different arrangement of spikes and concave clearance. The experiment was carried out and the whole procedure was repeated by varying the peripheral speed. 
There were three independent factors taken for the study i.e., arrangement of spikes, concave clearance and cylinder speed. Their effect was measured on dependent factors i.e., visible loss, invisible loss and threshing efficiency. Different helical arrangement of spikes forming helix was taken for the study, various level of concave clearance and cylinder speeds were also taken for the experimental purpose. A $50 \mathrm{~g}$ sample was taken for each experiment where broken grains were separated and weighed, so in this way we enumerate visible grain loss. With the help of illuminated purity board, internal cracks of the grain were determined for enumerating invisible grain loss. Unthreshed grains in the ear heads tell the effectiveness of threshing. Ratio of unthreshed grains to the threshed grains gives us the threshing efficiency. Different combination of independent factors were tried to figure out the best combination at which less loss (visible as well as invisible loss) and more profitability in terms of farmers benefit.

The data observed from various treatments was analyzed in terms of arrangement of spikes, cylinder speed and concave clearance and their effect was measured on each other for enumerating visible loss, invisible loss and threshing efficiency. The statistical analysis of the data was done by using Statistical Package for Social Sciences (SPSS, Version 22.0). Analysis was done considering the main effects and two factor interactions. Means were computed and tested at $5 \%$ level of significance.

In Design Expert 11, Response surface methodology (RSM) was very useful for the modeling and analysis of problems in which the response was influenced by several variables and the objective was to optimize this response. In Response surface methodology (RSM), tests were performed using different combinations of levels of the experiments according to the predetermined design, and an appropriate data was fitted to the data by the method of least squares. Three-dimensional plots provide a useful visual aid for checking the adequacy of the model and for examining the response surface and location of the optimum. Response surface methodology (RSM) was reported to be an efficient tool for optimizing a process when the independent variables have the joint effect on the responses Response surface methodology (RSM) also predict the equation in terms of coded factors about the response for given levels of each factor. By default, the high levels of the factors were coded as +1 and the low levels were coded as -1 . The coded equation was useful for identifying the relative impact of the factors by comparing the factor coefficients. It also provide the overall desirability plot and contour plots.

\section{Results And Discussion}

Field evaluation of experiment was carried out to assess the influence of independent design variable i.e., arrangement of spikes (AS) and independent operational parameters namely concave clearance (CC) and cylinder speed (CS). The study was aimed to quantify various combining losses viz., extent of grain damage (visible and invisible), unthreshed and clean grain losses in straw outlet at different arrangement of spikes, concave clearance and cylinder speed.

\section{Initial testing of conventional combine harvester on PUSA Basmati- 1121}

Initial testing of conventional combine harvester on PUSA Basmati-1121 to reduce the visible as well as invisible losses had been carried out at PAU Regional Research Station, Gurdaspur (Punjab) during the 
year 2017. Conventional combine harvester was operated at different arrangement of spikes, concave clearance and cylinder speed. The arrangement of spikes was kept at 44 spikes (AS1), 68 spikes (AS2) and 136 spikes (AS3) respectively. The concave clearance was kept at $13 \mathrm{~mm}$ at entry and $9 \mathrm{~mm}$ at the exit (CC1), $15 \mathrm{~mm}$ at entry and $11 \mathrm{~mm}$ at the exit (CC2) and $17 \mathrm{~mm}$ at entry and $13 \mathrm{~mm}$ at the exit (CC3) for conducting the experiments. The cylinder speed was kept at $560 \mathrm{rpm}$ (CS1), $640 \mathrm{rpm}$ (CS2) and $720 \mathrm{rpm}$ (CS3). Generally, as per the practice 68 spikes (AS2), $640 \mathrm{rpm}$ (CS2) and $15 \mathrm{~mm}$ at entry and $11 \mathrm{~mm}$ at the exit (CC2) was used by the manufacturer. Conventional combine harvester was generally operated in 2nd, low gear. The area for harvesting PUSA Basmati-1121 was 8 ha.

\section{Evaluation of experimental setup on PUSA Basmati- 1121 (Location: Regional Research Station, Gurdaspur, Punjab), 2017}

Field evaluation of the experimental setup was carried out on PUSA Basmati- 1121 during the year 2017. Harvesting and collection of the samples during field evaluation was carried out at Regional Research Station, Gurdaspur (Punjab). Subsequent analysis of small samples was carried out to assess the grain damage (both visible and invisible) and threshing efficiency. The effect of independent design parameters viz., arrangement of spikes (AS) and independent operational parameters namely concave clearance (CC) and cylinder speed (CS) on dependent variables viz., visible loss, invisible loss and threshing efficiency and results obtained have been discussed.

\section{Effect Of Independent Variables On Broken Grains (visible Loss):}

The data on fraction of broken grains (tank loss) as affected by arrangement of spikes, concave clearance and threshing efficiency was recorded. The changes in study variables were carried out in tangential cylinder of conventional combine harvester. Design parameter and operational parameter was varied in tangential cylinder. Arrangement of spikes (AS), concave clearance (CC) and cylinder speed (CS) for percent visible loss gives significant result as all the three factors contribute to the measurement of visible loss.

The interaction between AS and CC gives significant results in terms of visible loss, interaction between AS and CS gives non-significant results in terms of visible loss and interaction between CC and CS gives non-significant results in terms of visible loss. Statistical analysis revealed that interactions were significant for AS and CC as shown in Table 2. 
Table 2

ANOVA for percent visible loss in compartments- Basmati rice (PR-1121) (2017)

\begin{tabular}{|lllllll|}
\hline Source & DF & Sum of Squares & Mean Square & F Value & P Value & S/NS \\
\hline AS & 2 & 28.187 & 14.093 & 2205.62 & $<.0001$ & $S$ \\
\hline CC & 2 & 3.207 & 1.603 & 250.95 & $<.0001$ & $S$ \\
\hline CS & 2 & 4.729 & 2.365 & 370.05 & $<.0001$ & $S$ \\
\hline AS*CC & 4 & 0.109 & 0.027 & 4.28 & 0.0045 & $S$ \\
\hline AS*CS & 4 & 0.035 & 0.009 & 1.35 & 0.2622 & NS \\
\hline CC*CS & 4 & 0.063 & 0.016 & 2.45 & 0.0569 & NS \\
\hline
\end{tabular}

Effect of variation in visible loss on three levels of arrangement of spikes was studied at three levels of cylinder speed and concave clearance on percentage of broken grains. The mean percent broken grains collected at different arrangement of spikes AS1 (44 spikes), AS2 (68 spikes) and AS3 (136 spikes) on three levels of concave clearance CC1 (13 mm at entry and $9 \mathrm{~mm}$ at rear), CC2 (15 mm at entry and $11 \mathrm{~mm}$ at rear) and CC3 (17 mm at entry and $13 \mathrm{~mm}$ at rear) and three levels of cylinder speed CS1 (560 rpm), CS2 (640 rpm) and CS3 (720 rpm). Here, effect of arrangement of spikes AS1 (44 spikes) was taken into account and it was observed that visible loss increase with increase in cylinder speed, CS1 (560 rpm) gives minimized loss in terms of grain loss as compared to CS2 (640 rpm) and CS3 (720 rpm), CC3 (17 mm at entry and $13 \mathrm{~mm}$ at rear) gives minimum visible loss as compared to CC1 (13 $\mathrm{mm}$ at entry and $9 \mathrm{~mm}$ at rear) and CC2 (15 mm at entry and $11 \mathrm{~mm}$ at rear) as shown in Fig. 2. Further, it was concluded that percentage of broken grains range between 3.50 to $4.53 \%$ with helical arrangement of spikes (44 spikes) and variation in cylinder speed and concave clearance as compared to conventional combines where it has been reported to a maximum loss upto 8.1\% (Manes et al, 2002).

\section{Effect Of Independent Variables On Fissured Grains (invisible Loss):}

The data on fraction of fissured grains (tank loss) as affected by arrangement of spikes, concave clearance and threshing efficiency was recorded. The changes in study variables were carried out in tangential cylinder of conventional combine harvester. Design variable and operational parameter was varied in tangential cylinder. Arrangement of spikes (AS) for percent invisible loss gives significant result, concave clearance (CC) for percent invisible loss gives significant result and cylinder speed (CS) for percent invisible loss also gives significant result as all the three factors contribute to the measurement of invisible loss. The interaction between AS and CC gives non-significant results in terms of invisible loss, interaction between AS and CS gives non-significant results in terms of invisible loss and interaction between CC and CS gives non-significant results in terms of invisible loss. Statistical analysis revealed that interactions were non-significant as shown in Table 3. 
Table 3

ANOVA for percent invisible loss in compartments- Basmati rice (PR-1121) (2017)

\begin{tabular}{|lllllll|}
\hline Source & DF & Sum of Squares & Mean Square & F Value & P Value & S/NS \\
\hline AS & 2 & 756.247 & 378.123 & 134.80 & $<0.0001$ & $S$ \\
\hline CC & 2 & 232.691 & 116.346 & 41.48 & $<0.0001$ & $S$ \\
\hline CS & 2 & 118.914 & 59.457 & 21.20 & $<0.0001$ & $S$ \\
\hline AS ${ }^{*}$ CC & 4 & 27.457 & 6.864 & 2.45 & 0.0575 & NS \\
\hline AS ${ }^{*}$ CS & 4 & 0.790 & 0.198 & 0.07 & 0.9907 & NS \\
\hline CC*CS & 4 & 5.235 & 1.309 & 0.47 & 0.7600 & NS \\
\hline
\end{tabular}

Effect of variation in invisible loss on three levels of arrangement of spikes was studied at three levels of cylinder speed and concave clearance on percentage of cracked grains. The mean percent fissured grains collected at different arrangement of spikes AS1 (44 spikes), AS2 (68 spikes) and AS3 (136 spikes) on three levels of concave clearance CC1 (13 mm at entry and $9 \mathrm{~mm}$ at exit), CC2 (15 mm at entry and $11 \mathrm{~mm}$ at exit) and CC3 (17 mm at entry and $13 \mathrm{~mm}$ at exit) and three levels of cylinder speed CS1 (560 rpm), CS2 (640 rpm) and CS3 (720 rpm). Here, effect of arrangement of spikes AS1 (44 spikes) was taken into account and it was observed that invisible loss increases with increase in cylinder speed, CS1 (560 rpm) gives minimized loss in terms of grain loss as compared to CS2 (640 rpm) and CS3 (720 rpm), CC3 (17 mm at entry and $13 \mathrm{~mm}$ at exit) gives minimum invisible loss as compared to CC1 (13 $\mathrm{mm}$ at entry and $9 \mathrm{~mm}$ at exit) and CC2 (15 mm at entry and $11 \mathrm{~mm}$ at exit) as shown in Fig. 3. Further, it was concluded that percentage of fissured grains range between 17.33 to $24.67 \%$ with helical arrangement of spikes (44 spikes) and variation in cylinder speed and concave clearance as compared to conventional combines where it has been reported to a maximum loss upto $28 \%$ (Singh et al, 2001).

\section{Effect Of Independent Variables On Threshing Efficiency:}

It was observed that threshing was complete for all the treatment combinations. Therefore, any treatment can be considered optimum as far as threshing efficiency is concerned. 
Table 4

Mean values for arrangement of spikes of conventional combine harvester for Basmati rice (PUSA Basmati-1121)

\begin{tabular}{|llll|}
\hline AS (Arrangement of Spikes) & Visible Loss (\%) & $\begin{array}{l}\text { Invisible } \\
\text { Loss (\%) }\end{array}$ & Threshing Efficiency (\%) \\
\hline AS1 (44) & $4.05^{\mathrm{c}} \pm 0.34$ & $20.89^{\mathrm{b}} \pm 2.44$ & $99.32^{\mathrm{c}} \pm 0.47$ \\
\hline AS2 (68) & $4.83^{\mathrm{b}} \pm 0.32$ & $26.30^{\mathrm{a}} \pm 2.20$ & $99.77^{\mathrm{b}} \pm 0.33$ \\
\hline AS3 (136) & $5.49^{\mathrm{a}} \pm 0.33$ & $28.07^{\mathrm{a}} \pm 3.21$ & $99.89^{\mathrm{a}} \pm 0.17$ \\
\hline
\end{tabular}

AS1 (44 spikes) gives minimized loss i.e., $4.05 \pm 0.34 \%$ in terms of grain loss (Visible loss) as compared to AS2 (68 spikes) and AS3 (136 spikes). AS1 (44 spikes) gives minimum grain crackage i.e., $20.89 \pm$ $2.44 \%$ (Invisible loss) as compared to AS2 (68 spikes) and AS3 (136 spikes). Threshing efficiency was maximum in case of AS3 (136 spikes) i.e., $99.89 \pm 0.17 \%$ and minimum in case of AS1 (44 spikes) i.e., $99.32 \pm 0.47 \%$ with respect to AS2 (68 spikes) i.e., $99.77 \pm 0.33$. Mean values are expressed as \pm SD (Standard Deviation). Mean values followed with different superscripts are significantly different $(\mathrm{p}<$ 0.05) using Tukey's test.

Table 5

Mean values for concave clearance of conventional combine harvester for Basmati rice (PUSA Basmati-1121)

\begin{tabular}{|llll|}
\hline $\begin{array}{l}\text { CC } \\
\text { (Concave Clearance) }\end{array}$ & $\begin{array}{l}\text { Visible Loss } \\
(\%)\end{array}$ & $\begin{array}{l}\text { Invisible Loss } \\
(\%)\end{array}$ & Threshing Efficiency (\%) \\
\hline CC3 & $4.56^{\mathrm{c}} \pm 0.34$ & $22.96^{\mathrm{c}} \pm 2.44$ & $99.42^{\mathrm{c}} \pm 0.47$ \\
$(17-13 \mathrm{~mm})$ & & & \\
\hline CC2 & $4.77^{\mathrm{b}} \pm 0.32$ & $25.19^{\mathrm{b}} \pm 2.20$ & $99.71^{\mathrm{b}} \pm 0.33$ \\
$(15-11 \mathrm{~mm})$ & & & \\
\hline CC1 & $5.04^{\mathrm{a}} \pm 0.33$ & $27.11^{\mathrm{a}} \pm 3.21$ & $99.85^{\mathrm{a}} \pm 0.17$ \\
$(13-9 \mathrm{~mm})$ & & & \\
\hline
\end{tabular}

CC3 (17 mm at entry and $13 \mathrm{~mm}$ at exit) gives minimized loss i.e., $4.56 \pm 0.34 \%$ in terms of grain loss (Visible loss) as compared to CC2 (15 mm at entry and $11 \mathrm{~mm}$ at exit) and CC1 (13 mm at entry and $9 \mathrm{~mm}$ at exit). CC3 (17 mm at entry and $13 \mathrm{~mm}$ at exit) gives minimum grain crackage i.e., $22.96 \pm 2.44$ (Invisible loss) as compared to CC2 (15 mm at entry and $11 \mathrm{~mm}$ at exit) and CC3 (17 mm at entry and $13 \mathrm{~mm}$ at exit). Threshing efficiency was maximum in case of CC1 (13 $\mathrm{mm}$ at entry and $9 \mathrm{~mm}$ at exit) and minimum in case of CC3 (17 mm at entry and $13 \mathrm{~mm}$ at exit) with respect to CC2 (15 mm at entry and $11 \mathrm{~mm}$ at exit). Mean values were expressed as \pm SD (Standard Deviation). Mean values followed with different superscripts are significantly different $(p<0.05)$ using Tukey's test. 
Table 6

Mean values for cylinder speed of conventional combine harvester for Basmati rice (PUSA Basmati-1121)

\begin{tabular}{|llll|}
\hline CS & VL & IVL & TE \\
(Cylinder Speed) & $\begin{array}{l}\text { Visible Loss } \\
(\%)\end{array}$ & $\begin{array}{l}\text { Invisible Loss } \\
(\%)\end{array}$ & hreshing Efficiency (\%) \\
\hline CS1 & $4.47^{\mathrm{c}} \pm 0.34$ & $23.56^{\mathrm{c}} \pm 2.44$ & $99.40^{\mathrm{c}} \pm 0.47$ \\
$(560 \mathrm{rpm})$ & & & \\
CS2 & $4.84^{\mathrm{b}} \pm 0.32$ & $25.19^{\mathrm{b}} \pm 2.20$ & $99.70^{\mathrm{b}} \pm 0.33$ \\
$(640 \mathrm{rpm})$ & & & \\
\hline CS3 & $5.06^{\mathrm{a}} \pm 0.33$ & $26.52^{\mathrm{a}} \pm 3.21$ & $99.88^{\mathrm{a}} \pm 0.17$ \\
$(720 \mathrm{rpm})$ & & & \\
\hline
\end{tabular}

CS1 (560 rpm) gives minimized loss i.e., $4.47 \pm 0.34 \%$ in terms of grain loss (Visible loss) as compared to CS2 (640 rpm) and CS3 (720 rpm). CS1 (560 rpm) gives minimum grain crackage i.e., $23.56 \pm 2.44 \%$ as compared to CS2 $(640 \mathrm{rpm})$ and CS3 $(720 \mathrm{rpm})$. Threshing efficiency was maximum in case of CS3 (720 rpm) i.e., $99.88 \pm 0.17$ and minimum in case of CS1 (560 rpm) with respect to CS2 (640 rpm). Mean values are expressed as \pm SD (Standard Deviation). Mean values followed with different superscripts are significantly different $(p<0.05)$ using Tukey's test.

\section{Effect of header on grain loss of conventional combine harvester.}

The field experiment was performed to investigate the influence of cutting height and forward speed on header losses in PUSA Basmati- 1121 harvesting. The header losses were evaluated using conventional combine harvester equipped with a reel type header. The cutting height of $15 \mathrm{~cm}$ with forward speed of $1.5 \mathrm{~km} / \mathrm{h}$ had significant impact on grain damage. According to Bawatharani et al (2016), cutting height did not have any significant impact on grain damage. However, the forward speed of the harvester had substantial effect on decreasing the grain damage. So, header loss was in the range of 1.26 to $2.30 \%$ as forward speed is $1.5 \mathrm{~km} / \mathrm{h}$ which was the major cause of grain damage according to Bawatharani et al (2016).

\section{Effect of cylinder on grain loss of conventional combine harvester:}

The data on fraction of grains (broken or cracked) in cylinder loss as affected by arrangement of spikes (AS), concave clearance (CC) and cylinder speed (CS) was recorded. The changes in study variables were carried out in tangential cylinder of conventional combine harvester. Design variable and operational parameter was varied in tangential cylinder. Arrangement of spikes (AS), concave clearance (CC) and cylinder speed (CS) gives significant result, as all the three factors contribute to the measurement of visible loss, invisible loss and threshing efficiency similar to the tank loss. So, corresponding to the 
different arrangement of spikes, concave clearance and cylinder speed the range of broken grains, cracked grains and threshing efficiency was enumerated.

Effect of variation in visible loss on three levels of arrangement of spikes was studied at three levels of cylinder speed and concave clearance on percentage of broken grains. The mean percent broken grains collected at different arrangement of spikes AS1 (44 spikes), AS2 (68 spikes) and AS3 (136 spikes) on three levels of concave clearance CC1 (13 mm at entry and $9 \mathrm{~mm}$ at exit), CC2 (15 mm at entry and $11 \mathrm{~mm}$ at exit) and CC3 (17 mm at entry and $13 \mathrm{~mm}$ at exit) and three levels of cylinder speed CS1 (560 rpm), CS2 (640 rpm) and CS3 (720 rpm). Here, effect of arrangement of spikes AS1 (44 spikes) was taken into account and it was observed that visible loss increases with increase in cylinder speed, CS1 (560 rpm) gives minimized loss in terms of grain loss as compared to CS2 (640 rpm) and CS3 (720 rpm), CC3 (17 mm at entry and $13 \mathrm{~mm}$ at rear) gives minimum visible loss as compared to CC1 (13 $\mathrm{mm}$ at entry and $9 \mathrm{~mm}$ at rear) and CC2 (15 mm at entry and $11 \mathrm{~mm}$ at rear) as shown in Fig. 4. Further, it was concluded that percentage of broken grains range between 2.59 to $3.64 \%$ with helical arrangement of spikes (44 spikes) and variation in cylinder speed and concave clearance as compared to conventional combines where it has been reported to a maximum loss upto $8.1 \%$ (Manes et al, 2002).

Effect of variation in invisible loss on three levels of arrangement of spikes was studied at three levels of cylinder speed and concave clearance on percentage of broken grains. The mean percent fissured grains collected at different arrangement of spikes AS1 (44 spikes), AS2 (68 spikes) and AS3 (136 spikes) on three levels of concave clearance CC1 (13 mm at entry and $9 \mathrm{~mm}$ at exit), CC2 (15 mm at entry and $11 \mathrm{~mm}$ at exit) and CC3 (17 mm at entry and $13 \mathrm{~mm}$ at exit) and three levels of cylinder speed CS1 (560 rpm), CS2 (640 rpm) and CS3 (720 rpm).

Here, effect of arrangement of spikes AS1 (44 spikes) was taken into account and it was observed that invisible loss increases with increase in cylinder speed, CS1 (560 rpm) gives minimized loss in terms of grain loss as compared to CS2 (640 rpm) and CS3 (720 rpm), CC3 (17 mm at entry and $13 \mathrm{~mm}$ at exit) gives minimum invisible loss as compared to CC1 (13 mm at entry and $9 \mathrm{~mm}$ at exit) and CC2 (15 mm at entry and $11 \mathrm{~mm}$ at exit). Further, it was concluded that percentage of fissured grains range between 13.33 to $20.67 \%$ with helical arrangement of spikes (44 spikes) and variation in cylinder speed and concave clearance as compared to conventional combines where it has been reported to a maximum loss upto $28 \%$ (Singh et al, 2001).

Threshing efficiency was almost complete i.e., it comes in the range of 98 to more than $99 \%$ as per BIS code.

\section{Effect of sieve and straw walker loss of conventional combine harvester:}

Straw walker loss including threshed grain which ranges between 0.21 to $1.14 \%$, unthreshed grain which range between 0.00 to $0.09 \%$ and broken grain which ranges between 0.00 to $0.02 \%$. So, major loss in straw walker loss was threshed grain which was collected in a $10 \mathrm{~m}$ long cloth for $20 \mathrm{~s}$. Unthreshed and broken grain percentage was negligible and hence neglected. 
Sieve loss including threshed grain which ranges between 0.34 to $1.34 \%$, unthreshed grain which ranges between 0.00 to $0.06 \%$ and broken grain which ranges between 0.00 to $0.01 \%$. So, major loss in sieve loss was threshed grain collected in a $10 \mathrm{~m}$ long cloth for $20 \mathrm{~s}$. Unthreshed and broken grain percentage was negligible and hence neglected.

\section{Optimization Of Design Variable And Operational Parameters, 2017}

The response surface and contour plots were generated for different interaction of any two independent variables, while holding the value of one variable constant. Such three dimensional surfaces could give accurate geometrical representation and provide useful information about the behaviour of the system within the experimental design. For both arrangement of spikes ( $A S=1, A S=2$ and $A S=3$ ) and concave clearance $(C C=1, C C=2$ and $C C=3)$, the data of the experimental studies and the responses measured for cylinder speed $(C S=1, C S=2$ and $C S=3$ ) for optimization of selected design variable and operational parameters of threshing mechanism of conventional combine harvester for basmati rice.

\section{Visible Loss (response 1: VI)}

\section{Final equation in terms of coded factors}

$\mathrm{VL}=+4.85+0.7233 \mathrm{a}-0.2402 \mathrm{~B}+0.2782 \mathrm{C}-0.0767 \mathrm{aB}-0.1133 \mathrm{aC}-0.0342 \mathrm{BC}-0.1101 \mathrm{a}^{2}-$ $0.0288 B^{2}-0.0548 C^{2}$

where VL = Visible loss, $\mathrm{a}=\mathrm{AS}$ (Arrangement of spikes), $\mathrm{B}=\mathrm{CC}$ (Concave clearance) and $\mathrm{C}=\mathrm{CS}$ (Cylinder speed)

The equation in terms of coded factors can be used to make predictions about the response for given levels of each factor. By default, the high levels of the factors were coded as +1 and the low levels are coded as -1 . The coded equation was useful for identifying the relative impact of the factors by comparing the factor coefficients.

\section{Final equation in terms of actual factors}

$\mathrm{VL}=+1.65702+1.54365 \mathrm{AS}+0.096706 \mathrm{CC}+0.792353 \mathrm{CS}-0.076667 \mathrm{AS}^{*} \mathrm{CC}-0.113333 \mathrm{AS}{ }^{*} \mathrm{CS}-$ $0.034196 C C^{\star} C S-0.110078 A S^{2}-0.028784 C C^{2}-0.054784 C S^{2}$

where VL = Visible loss, AS = Arrangement of spikes, $C C=$ Concave clearance and CS $=$ Cylinder speed

The equation in terms of actual factors can be used to make predictions about the response for given levels of each factor. Here, the levels should be specified in the original units for each factor. This equation should not be used to determine the relative impact of each factor because the coefficients were 
scaled to accommodate the units of each factor and the intercept was not at the center of the design space.

In contour plots, there were three factors viz., arrangement of spikes (AS), concave clearance (CC) and cylinder speed (CS) with actual factor is cylinder speed (CS), $X_{1}=A S$ (arrangement of spikes) and $X_{2}=C C$ (Concave clearance). Low axis was taken as 1 and high axis was taken as 3 with a combination of $A S=1$ (44 spikes), CC = $3(17 \mathrm{~mm}$ at entry and $13 \mathrm{~mm}$ at exit) and CS $=1(560 \mathrm{rpm})$ at which visible loss was minimum i.e., $3.42 \%$. The range of visible loss was between 3.42 to $5.74 \%$ as shown in Fig. 6 .

In contour plots, there were three factors viz., arrangement of spikes (AS), concave clearance (CC) and cylinder speed (CS) with actual factor was concave clearance (CC), $\mathrm{X}_{1}=$ AS (arrangement of spikes) and $\mathrm{X}_{2}=\mathrm{CS}$ (cylinder speed). Low axis was taken as 1 and high axis was taken as 3 with a combination of AS $=1$ (44 spikes), $C C=3(17 \mathrm{~mm}$ at entry and $13 \mathrm{~mm}$ at exit) and $C S=1(560 \mathrm{rpm})$ at which visible loss was minimum i.e., $3.42 \%$. The range of visible loss was between 3.42 to $5.74 \%$ as shown in Fig. 7 .

In contour plots, there were three factors viz., arrangement of spikes (AS), concave clearance (CC) and cylinder speed (CS) with actual factor is arrangement of spikes (AS), $X_{1}=C C$ (concave clearance) and $X_{2}$ $=\mathrm{CS}$ (cylinder speed). Low axis was taken as 1 and high axis was taken as 3 with a combination of AS $=$ 1 (44 spikes), $C C=3$ (17 mm at entry and $13 \mathrm{~mm}$ at exit) and $C S=1(560 \mathrm{rpm})$ at which visible loss was minimum i.e., $3.42 \%$. The range of visible loss was between 3.42 to $5.74 \%$ as shown in Fig. 8 .

In response surface plots, there were three factors viz., arrangement of spikes (AS), concave clearance (CC) and cylinder speed (CS) with actual factor is cylinder speed (CS), $\mathrm{X}_{1}=$ AS (arrangement of spikes) and $\mathrm{X}_{2}=\mathrm{CC}$ (concave clearance). Low axis was taken as 1 and high axis was taken as 3 with a combination of $A S=1$ (44 spikes), $C C=3(17 \mathrm{~mm}$ at entry and $13 \mathrm{~mm}$ at exit) and $\mathrm{CS}=1$ (560 rpm) at which visible loss was minimum i.e., $3.42 \%$. The range of visible loss was between 3.42 to $5.74 \%$ as shown in Fig. 9.

In response surface plots, there were three factors viz., arrangement of spikes (AS), concave clearance (CC) and cylinder speed (CS) with actual factor is concave clearance (CC), $\mathrm{X}_{1}=$ AS (arrangement of spikes) and $\mathrm{X}_{2}=\mathrm{CS}$ (cylinder speed). Low axis was taken as 1 and high axis was taken as 3 with a combination of $A S=1$ (44 spikes), $C C=3(17 \mathrm{~mm}$ at entry and $13 \mathrm{~mm}$ at exit) and $C S=1(560 \mathrm{rpm})$ at which visible loss was minimum i.e., $3.42 \%$. The range of visible loss was between 3.42 to $5.74 \%$ as shown in Fig. 10.

In response surface plots, there were three factors viz., arrangement of spikes (AS), concave clearance (CC) and cylinder speed (CS) with actual factor is arrangement of spikes (AS), $\mathrm{X}_{1}=\mathrm{CC}$ (concave clearance) and $\mathrm{X}_{2}=\mathrm{CS}$ (cylinder speed). Low axis was taken as 1 and high axis was taken as 3 with a combination of $A S=1$ (44 spikes), $C C=3(17 \mathrm{~mm}$ at entry and $13 \mathrm{~mm}$ at exit) and $\mathrm{CS}=1$ (560 rpm) at which visible loss was minimum i.e., $3.42 \%$. The range of visible loss was between 3.42 to $5.74 \%$ as shown in Fig. 11. 


\section{Invisible Loss (response 2: Ivl)}

\section{Final equation in terms of coded factors}

$I V L=+26.66+4.00 a-2.56 B+1.36 C+0.0000 a B+2.00 a C+0.2039 B C-1.68 a^{2}-0.3843 B^{2}+0.3843$ $B^{2}+0.0157 C^{2}$

where IVL = Invisible loss, a = Arrangement of spikes (AS), B = Concave clearance (CC) and C = Cylinder speed (CS)

The equation in terms of coded factors can be used to make predictions about the response for given levels of each factor. By default, the high levels of the factors were coded as +1 and the low levels were coded as -1 . The coded equation was useful for identifying the relative impact of the factors by comparing the factor coefficients.

\section{Final equation in terms of actual factors}

$\mathrm{IVL}=+21.68627+6.71373 \mathrm{AS}-1.42745 \mathrm{CC}-3.11373 \mathrm{CS}+4.72030 \mathrm{E}-16 \mathrm{AS}{ }^{*} \mathrm{CC}+2.00000 \mathrm{AS}{ }^{*} \mathrm{CS}+$ $0.203922 C C^{*} C S-1.67843 A S^{2}-0.384314 C C^{2}+0.015686 C S^{2}$

where IVL = Invisible loss, AS = Arrangement of spikes, CC = Concave clearance and CS = Cylinder speed

The equation in terms of actual factors can be used to make predictions about the response for given levels of each factor. Here, the levels should be specified in the original units for each factor. This equation should not be used to determine the relative impact of each factor because the coefficients were scaled to accommodate the units of each factor and the intercept was not at the center of the design space.

In contour plots, there were three factors viz., arrangement of spikes (AS), concave clearance (CC) and cylinder speed (CS) with actual factor is cylinder speed (CS), $X_{1}=$ AS (Arrangement of spikes) and $X_{2}=C C$ (Concave clearance). Low axis was taken as 1 and high axis was taken as 3 with a combination of $A S=1$ (44 spikes), $\mathrm{CC}=3$ (17 $\mathrm{mm}$ at entry and $13 \mathrm{~mm}$ at exit) and $\mathrm{CS}=1(560 \mathrm{rpm})$ at which invisible loss was minimum i.e., $18 \%$. The range of invisible loss was between 18 to $32 \%$ as shown in Fig. 12 .

In contour plots, there were three factors viz., arrangement of spikes (AS), concave clearance (CC) and cylinder speed (CS) with actual factor is concave clearance (CC), $X_{1}=$ AS (arrangement of spikes) and $X_{2}$ $=\mathrm{CS}$ (cylinder speed). Low axis was taken as 1 and high axis was taken as 3 with a combination of AS = 1 (44 spikes), $C C=3$ (17 mm at entry and $13 \mathrm{~mm}$ at exit) and CS $=1$ (560 rpm) at which invisible loss was minimum i.e., 18. The range of invisible loss was between 18 to $32 \%$ as shown in Fig. 13 .

In contour plots, there were three factors viz., arrangement of spikes (AS), concave clearance (CC) and cylinder speed (CS) with actual factor is arrangement of spikes (AS), $X_{1}=C C$ (concave clearance) and $X_{2}$ = CS (cylinder speed). Low axis was taken as 1 and high axis was taken as 3 with a combination of $A S=$ 
1 (44 spikes), $\mathrm{CC}=3$ (17 $\mathrm{mm}$ at entry and $13 \mathrm{~mm}$ at exit) and $\mathrm{CS}=1(560 \mathrm{rpm})$ at which invisible loss is minimum i.e., $18 \%$. The range of invisible loss was between 18 to $32 \%$ as shown in Fig. 14 .

In response surface plots, there were three factors viz., arrangement of spikes (AS), concave clearance (CC) and cylinder speed (CS) with actual factor is cylinder speed (CS), $\mathrm{X}_{1}=$ AS (Arrangement of spikes) and $\mathrm{X}_{2}=\mathrm{CC}$ (Concave clearance). Low axis was taken as 1 and high axis was taken as 3 with a combination of $A S=1$ (44 spikes), $C C=3(17 \mathrm{~mm}$ at entry and $13 \mathrm{~mm}$ at exit) and $\mathrm{CS}=1$ (560 rpm) at which invisible loss was minimum i.e., $18 \%$. The range of invisible loss was between 18 to $32 \%$ as shown in Fig. 15.

In response surface plots, there were three factors viz., arrangement of spikes (AS), concave clearance (CC) and cylinder speed (CS) with actual factor is concave clearance (CC), $X_{1}=$ AS (arrangement of spikes) and $X_{2}=C S$ (cylinder speed). Low axis was taken as 1 and high axis was taken as 3 with a combination of $A S=1$ (44 spikes), $C C=3(17 \mathrm{~mm}$ at entry and $13 \mathrm{~mm}$ at exit) and $C S=1(560 \mathrm{rpm})$ at which invisible loss was minimum i.e., $18 \%$. The range of invisible loss was between 18 to $32 \%$ as shown in Fig. 16.

In response surface plots, there were three factors viz., arrangement of spikes (AS), concave clearance (CC) and cylinder speed (CS) with actual factor is arrangement of spikes (AS), $\mathrm{X}_{1}=\mathrm{CC}$ (concave clearance) and $\mathrm{X}_{2}=\mathrm{CS}$ (cylinder speed). Low axis was taken as 1 and high axis was taken as 3 with a combination of $A S=1$ (44 spikes), $C C=3(17 \mathrm{~mm}$ at entry and $13 \mathrm{~mm}$ at exit) and $C S=1(560 \mathrm{rpm})$ at which invisible loss is minimum i.e., $18 \%$. The range of invisible loss was between 18 to $32 \%$ as shown in Fig. 17.

\section{Threshing Efficiency (response 3: Te)}

\section{Final equation in terms of coded factors}

$T E=+99.920+0.1587 a-0.1670 B+0.1910 C+0.0692 a B-0.1337 a C+0.1632 B C-0.1397 a^{2}-$ $0.0878 B^{2}-0.0518 C^{2}$

where TE $=$ Threshing efficiency, $a=$ AS (Arrangement of spikes), $B=C C$ (Concave clearance) and $C=C S$ (Cylinder speed)

The equation in terms of coded factors can be used to make predictions about the response for given levels of each factor. By default, the high level of the factors was coded as +1 and the low level was coded as -1 . The coded equation was useful for identifying the relative impact of the factors by comparing the factor coefficients.

\section{Final Equation In Terms Of Actual Factors}


$\mathrm{TE}=+98.82806+0.846271 \mathrm{AS}-0.280441 \mathrm{CC}+0.339229 \mathrm{CS}+0.069167 \mathrm{AS}{ }^{\star} \mathrm{CC}-0.133667 \mathrm{AS}{ }^{\star} \mathrm{CS}+$ $0.163173 C C^{*} C S-0.139651 A S^{2}-0.087810 C C^{2}-0.051810 C S^{2}$

where TE $=$ Threshing efficiency, AS $=$ Arrangement of spikes, $C C=$ Concave clearance and CS $=$ Cylinder speed

The equation in terms of actual factors can be used to make predictions about the response for given levels of each factor. Here, the levels should be specified in the original units for each factor. This equation should not be used to determine the relative impact of each factor because the coefficients were scaled to accommodate the units of each factor and the intercept was not at the center of the design space.

In contour plots, there were three factors viz., arrangement of spikes (AS), concave clearance (CC) and cylinder speed (CS) with actual factor is cylinder speed (CS), $X_{1}=A S$ (Arrangement of spikes) and $X_{2}=C C$ (Concave clearance). Low axis was taken as 1 and high axis was taken as 3 with a combination of AS $=1$ (44 spikes), CC = 3 (17 $\mathrm{mm}$ at entry and $13 \mathrm{~mm}$ at exit) and CS $=1(560 \mathrm{rpm})$ at which threshing efficiency was minimum i.e., $98.706 \%$. The range of threshing efficiency was between 98.706 to $99.971 \%$ as shown in Fig. 18.

In contour plots, there were three factors viz., arrangement of spikes (AS), concave clearance (CC) and cylinder speed (CS) with actual factor is concave clearance (CC), $X_{1}=$ AS (arrangement of spikes) and $X_{2}$ $=\mathrm{CS}$ (cylinder speed). Low axis was taken as 1 and high axis was taken as 3 with a combination of $A S=$ 1 (44 spikes), $C C=3$ (17 mm at entry and $13 \mathrm{~mm}$ at exit) and CS $=1$ (560 rpm) at which threshing efficiency was minimum i.e., $98.706 \%$. The range of threshing efficiency was between 98.706 to $99.971 \%$ as shown in Fig. 19.

In contour plots, there were three factors viz., arrangement of spikes (AS), concave clearance (CC) and cylinder speed (CS) with actual factor is arrangement of spikes (AS), $X_{1}=C C$ (concave clearance) and $X_{2}$ $=\mathrm{CS}$ (cylinder speed). Low axis was taken as 1 and high axis was taken as 3 with a combination of AS $=$ 1 (44 spikes), CC = 3 (17 mm at entry and $13 \mathrm{~mm}$ at exit) and CS $=1$ (560 rpm) at which threshing efficiency was minimum i.e., $98.706 \%$. The range of threshing efficiency was between 98.706 to $99.971 \%$ as shown in Fig. 20.

In response surface plots, there were three factors viz., arrangement of spikes (AS), concave clearance (CC) and cylinder speed (CS) with actual factor is cylinder speed (CS), $\mathrm{X}_{1}=$ AS (Arrangement of spikes) and $\mathrm{X}_{2}=\mathrm{CC}$ (Concave clearance). Low axis was taken as 1 and high axis was taken as 3 with a combination of $A S=1$ (44 spikes), $C C=3(17 \mathrm{~mm}$ at entry and $13 \mathrm{~mm}$ at exit) and CS $=1$ (560 rpm) at which threshing efficiency was minimum i.e., $98.706 \%$. The range of threshing efficiency was between 98.706 to $99.971 \%$ as shown in Fig. 21.

In response surface plots, there were three factors viz., arrangement of spikes (AS), concave clearance (CC) and cylinder speed (CS) with actual factor is concave clearance (CC), $\mathrm{X}_{1}=\mathrm{AS}$ (arrangement of 
spikes) and $\mathrm{X}_{2}=\mathrm{CS}$ (cylinder speed). Low axis was taken as 1 and high axis was taken as 3 with a combination of $A S=1$ (44 spikes), $C C=3(17 \mathrm{~mm}$ at entry and $13 \mathrm{~mm}$ at exit) and CS $=1$ (560 rpm) at which threshing efficiency was minimum i.e., $98.706 \%$. The range of threshing efficiency was between 98.706 to $99.971 \%$ as shown in Fig. 22.

In response surface plots, there were three factors viz., arrangement of spikes (AS), concave clearance (CC) and cylinder speed (CS) with actual factor is arrangement of spikes (AS), $\mathrm{X}_{1}=\mathrm{CC}$ (concave clearance) and $\mathrm{X}_{2}=\mathrm{CS}$ (cylinder speed). Low axis was taken as 1 and high axis was taken as 3 with a combination of $A S=1$ (44 spikes), $C C=3(17 \mathrm{~mm}$ at entry and $13 \mathrm{~mm}$ at exit) and CS $=1$ (560 rpm) at which threshing efficiency was minimum i.e., $98.706 \%$. The range of threshing efficiency was between 98.706 to $99.971 \%$ as shown in Fig. 23.

On the basis of results obtained following conclusions were drawn:

1. For arrangement of spikes 44,68 and 136 spikes were investigated and found that 44 spikes gives minimized losses in terms of grain loss (visible and invisible loss).

2. For concave clearance $13-9,15-11$ and $17-13 \mathrm{~mm}$ were investigated and found that $17-13 \mathrm{~mm}$ gives minimized losses in terms of grain loss (visible and invisible loss).

3. For cylinder speed 560, 640 and $720 \mathrm{rpm}$ were investigated and found that $560 \mathrm{rpm}$ gives minimized losses in terms of grain loss (visible and invisible loss).

4. AS1CC3CS1 (44 spikes, $17-13 \mathrm{~mm}$ and $560 \mathrm{rpm}$ ) was better combination as it minimized the visible loss to $3.50 \%$, it also minimized the invisible loss to $17.33 \%$.

5. Optimum values obtained through optimization at this combination of AS1CC3CS1 where visible loss was $3.42 \%$, invisible loss was $18 \%$ and threshing efficiency was $98.706 \%$ for the year 2017 .

\section{Abbreviations}




\begin{tabular}{|ll|}
\hline $\mathrm{m}$ & Meter \\
\hline $\mathrm{g}$ & gram \\
\hline $\mathrm{s}$ & Second \\
\hline $\mathrm{mm} / \mathrm{s}$ & Millimeter \\
\hline $\mathrm{kg} / \mathrm{h}$ & Meter per second \\
\hline rpm & Revolutions per minute \\
\hline H.P. & Horse power \\
\hline etc & Etcetera \\
\hline et al & and other \\
\hline i.e. & that is \\
\hline Fig. & Figure \\
\hline w.b. & Wet basis \\
\hline $\mathrm{t}$ & Tonnes \\
o $\mathrm{C}$ & Degree Centigrate \\
SPSS & Statistical Package for Social Sciences \\
RSM & Response surface methodology \\
BIS & Bureau of Indian standards \\
VL & Visible loss \\
IVL & Invisible loss \\
TE & Threshing efficiency \\
\hline
\end{tabular}

\section{Declarations}

\section{Ethical Approval and Consent to participate:}

We wish to confirm that this is not applicable in this study.

\section{Consent for publication:}

We wish to confirm that this is not applicable in this study.

\section{Availability of data and material:}


All data generated or analyzed during this study are included in this published article (and its supplementary information files).

\section{Competing interests:}

The authors declare that they have no competing interests in this section.

\section{Funding:}

We confirm that there no funding is provided in the design of the study and collection, analysis, and interpretation of data and in writing the manuscript.

\section{Authors' contributions:}

We confirm that the manuscript has been read and approved by all named authors and that there are no other persons who satisfied the criteria for authorship but are not listed. We further confirm that the order of authors listed in the manuscript has been approved by all of us.

\section{Acknowledgements:}

We wish to confirm that this is not applicable in this study.

8. We confirm that we have given due consideration to the protection of intellectual property associated with this work and that there are no impediments to publication, including the timing of publication, with respect to intellectual property. In so doing we confirm that we have followed the regulations of our institutions concerning intellectual property.

9. We understand that the Corresponding Author is the sole contact for the Editorial process (including Editorial Manager and direct communications with the office). He/she is responsible for communicating with the other authors about progress, submissions of revisions and final approval of proofs. We confirm that we have provided a current, correct email address which is accessible by the Corresponding Author and which has been configured to accept email from (ritudogra@pau.edu)

\section{References}

1. Anonymous (2015) Agricultural statistics at a glance-2015. Pp 83-85. Department of agriculture, cooperation \& farmer's welfare, ministry of agriculture \& farmer's welfare, Government of India

2. Anonymous (2018-19) Basmati_Report.pdf

3. Bawatharani R, Bandara MHMA, Senevirathne DIE (2016) Influence of Cutting Height and Forward Speed on Header Losses in Rice Harvesting. Intl J Agl Fo PI 4:1-9

4. DePauw AR, Francis RL, Snyder HC (1977) Engineering aspects of axial flow combine design. Paper no 77-1550, Presented at 1977 winter meeting of ASAE held at Chicago, Illinois from Dec 13-16, 1977 
5. Kutzbach HD, Quick GR (1999) Harvesters and Grain Threshers. In: Stout BA, Cheze B (eds) CIGR Handbook of Agricultural Engineering Vol, 111- Plant Protection Engineering.. ASAE, St Joseph MI, USA, pp 311-346

6. Manes GS, Sandhar NS, Bal AS, Khurana HM (2002) Comparative performance of combine harvesters. Agril Engg Today 27:7-14

7. Singh A, Garg IK, Sharma VK (2001) Effect of different crop and operational parameters of a combine on grain damage during paddy harvesting. J Res Punjab Agricultural University 38:241-252

\section{Figures}

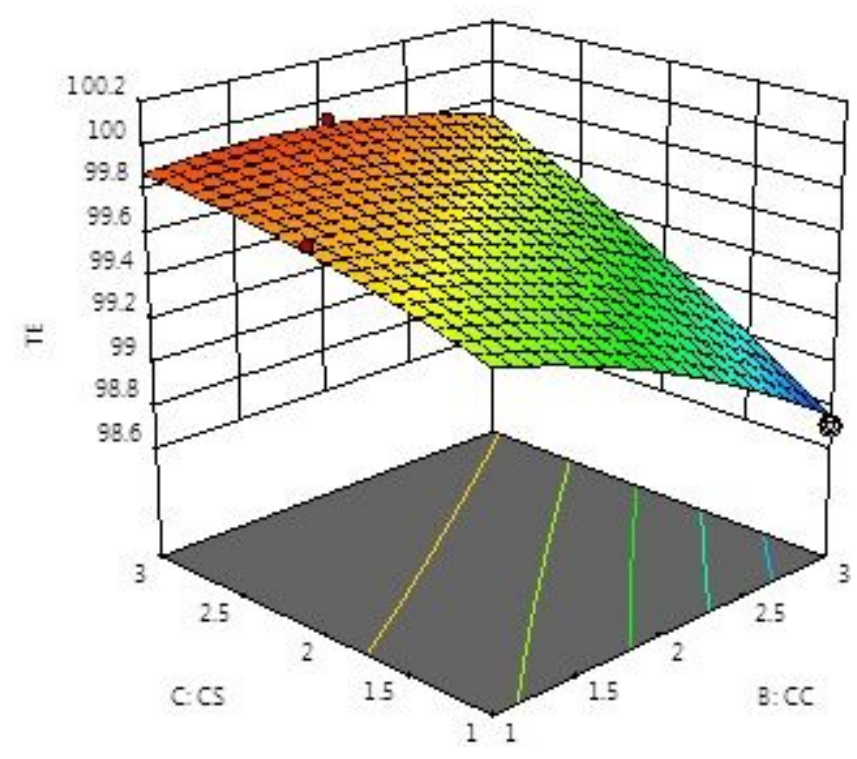

\section{Figure 1}

Response surface plots for arrangement of spikes $(A S=1)$, concave clearance $(C C=3)$ and cylinder speed $(C S=1)$ with a Threshing efficiency $=98.706 \%$ 


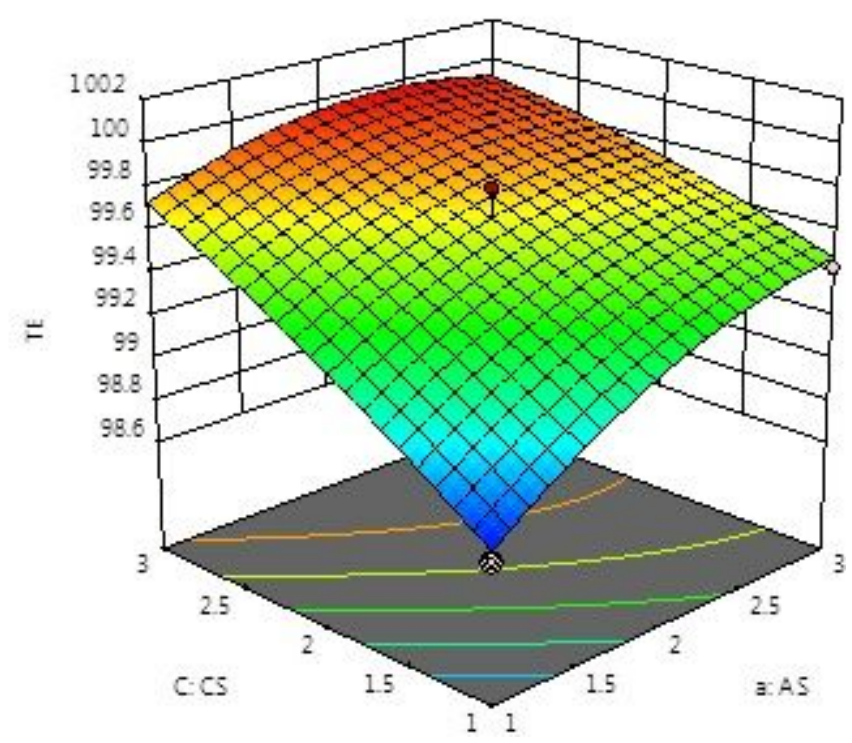

\section{Figure 2}

Response surface plots for arrangement of spikes (AS $=1)$, concave clearance $(C C=3)$ and cylinder speed $(C S=1)$ with a Threshing efficiency $=98.706 \%$

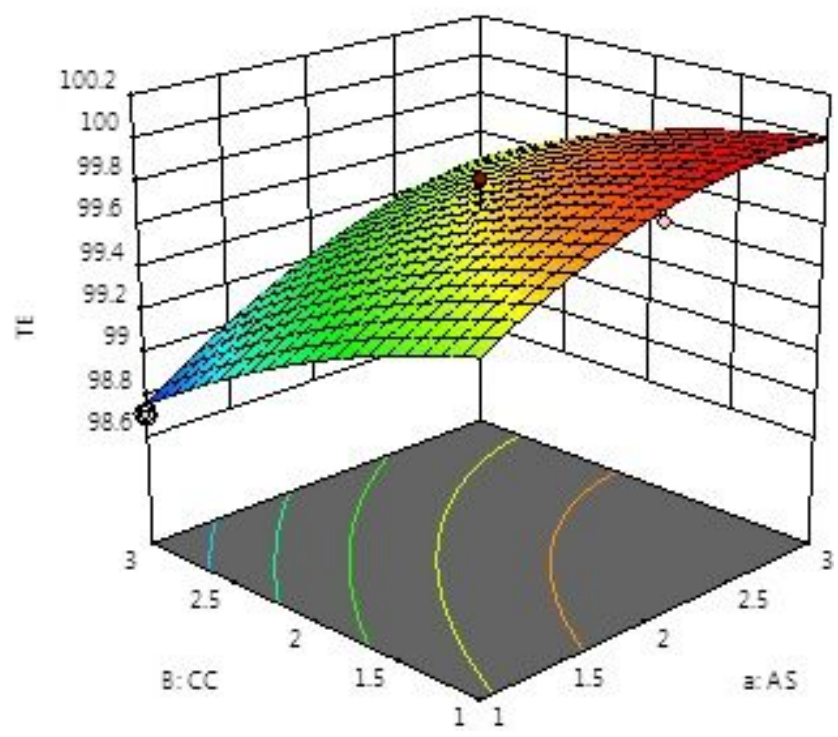

\section{Figure 3}

Response surface plots for arrangement of spikes (AS $=1)$, concave clearance $(C C=3)$ and cylinder speed $(C S=1)$ with a Threshing efficiency $=98.706 \%$ 


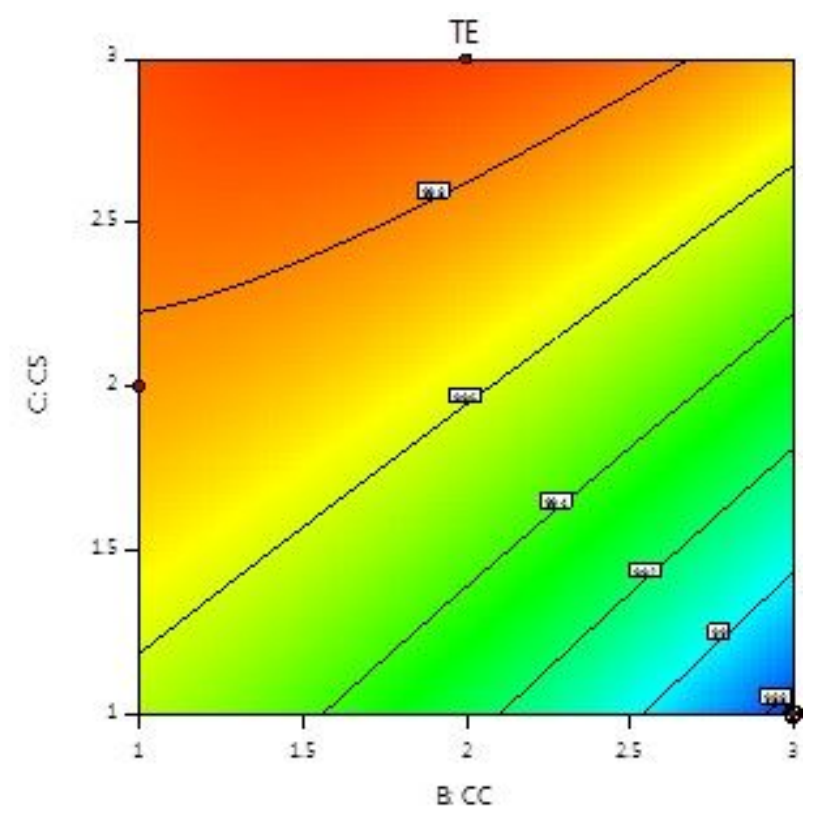

Figure 4

Contour plots for arrangement of spikes $(A S=1)$, concave clearance $(C C=3)$ and cylinder speed $(C S=1)$ with a Threshing efficiency $=98.706 \%$

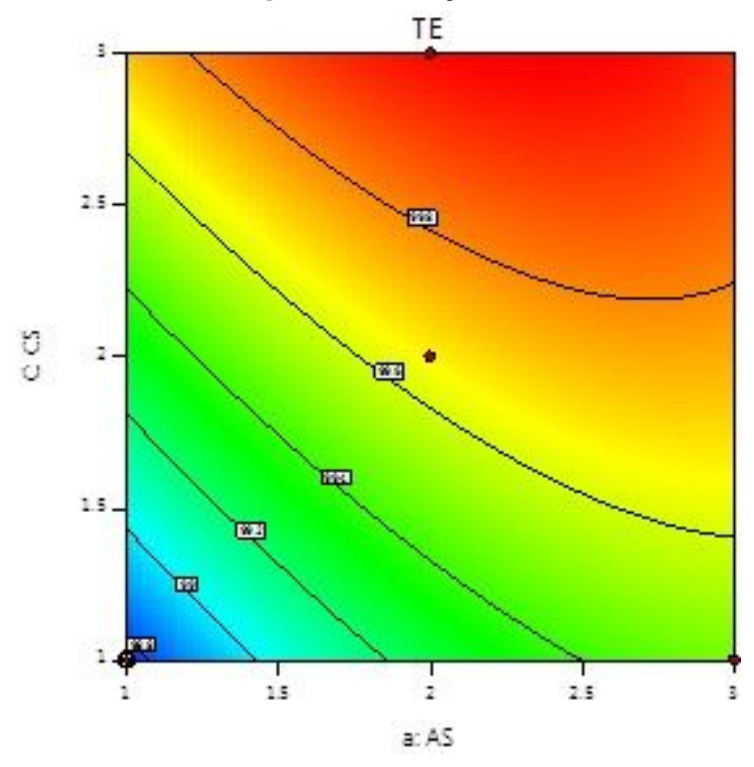

\section{Figure 5}

Contour plots for arrangement of spikes $(A S=1)$, concave clearance $(C C=3)$ and cylinder speed $(C S=1)$ with a Threshing efficiency $=98.706 \%$ 


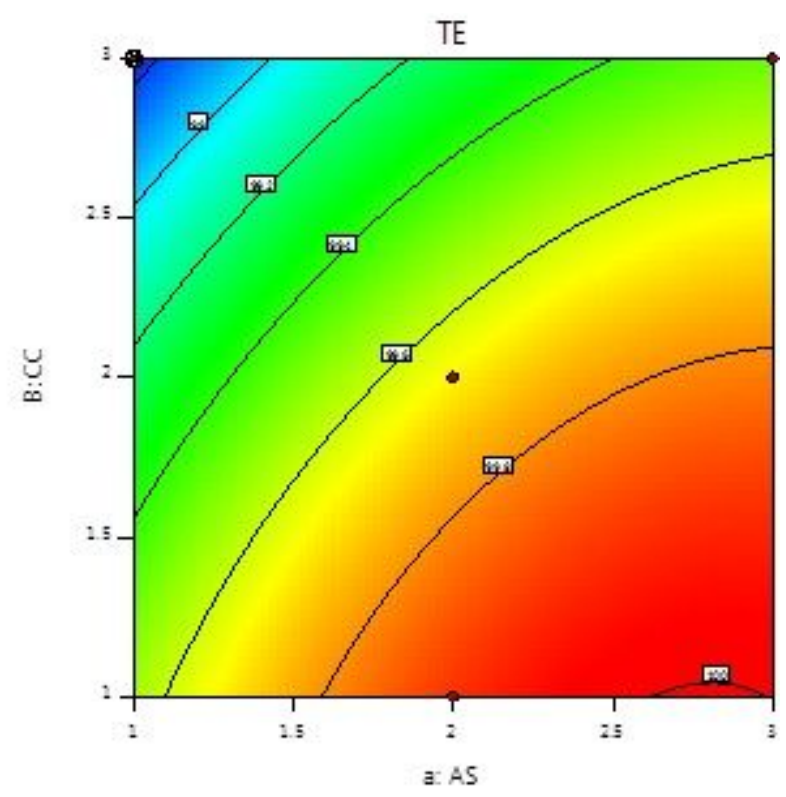

Figure 6

Contour plots for arrangement of spikes $(A S=1)$, concave clearance $(C C=3)$ and cylinder speed $(C S=1)$ with a Threshing efficiency $=98.706 \%$

$\bar{z}$

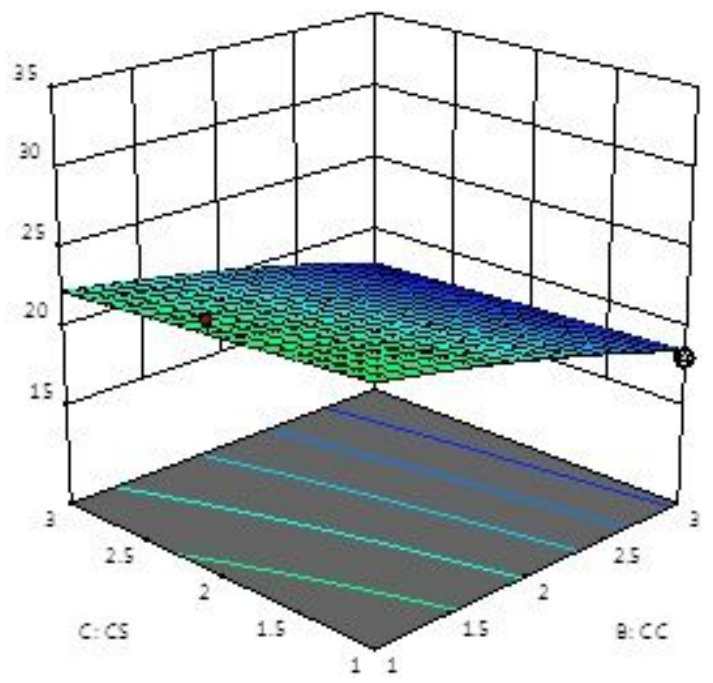

Figure 7

Response surface plots of arrangement of spikes (AS $=1)$, concave clearance $(C C=3)$ and cylinder speed $(\mathrm{CS}=1)$ with a Invisible loss $=18 \%$ 


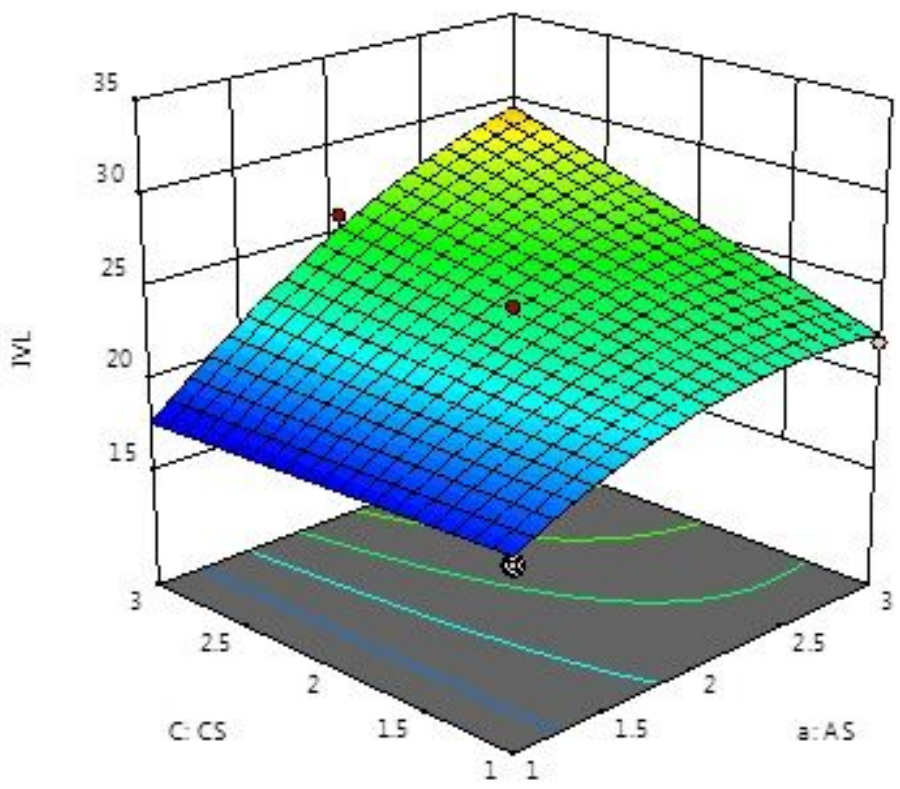

Figure 8

Response surface plots of arrangement of spikes $(A S=1)$, concave clearance $(C C=3)$ and cylinder speed $(C S=1)$ with a Invisible loss $=18 \%$

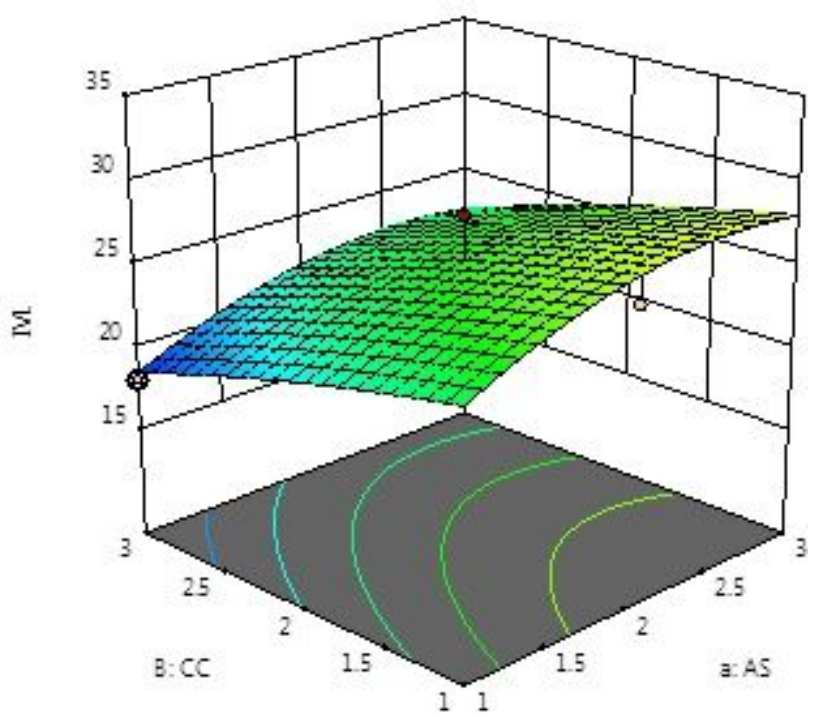

Figure 9

Response surface plots of arrangement of spikes $(A S=1)$, concave clearance $(C C=3)$ and cylinder speed $(C S=1)$ with a Invisible loss $=18 \%$ 


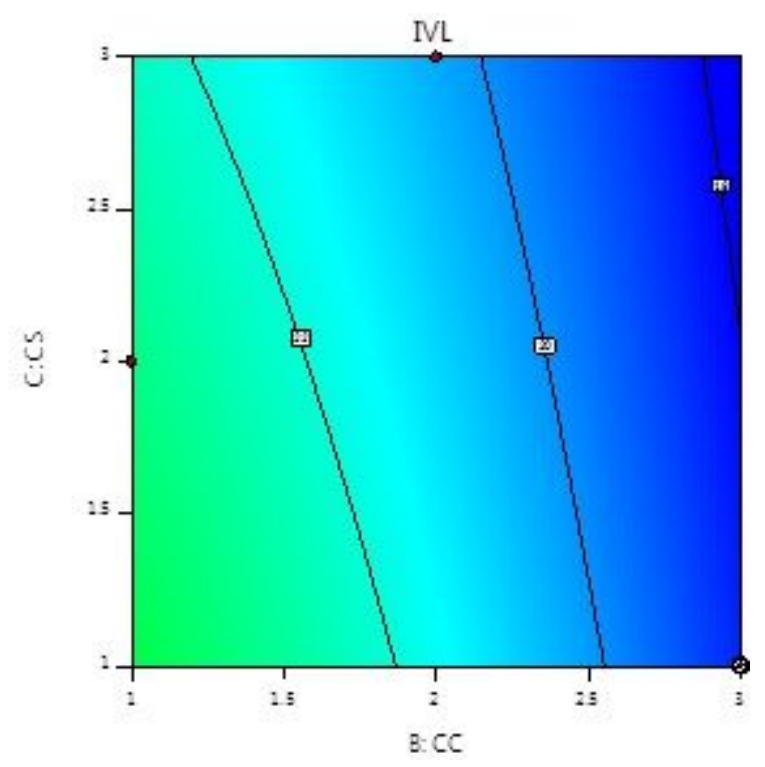

Figure 10

Contour plots for arrangement of spikes $(A S=1)$, concave clearance $(C C=3)$ and cylinder speed $(C S=1)$ with a Invisible loss $=18 \%$

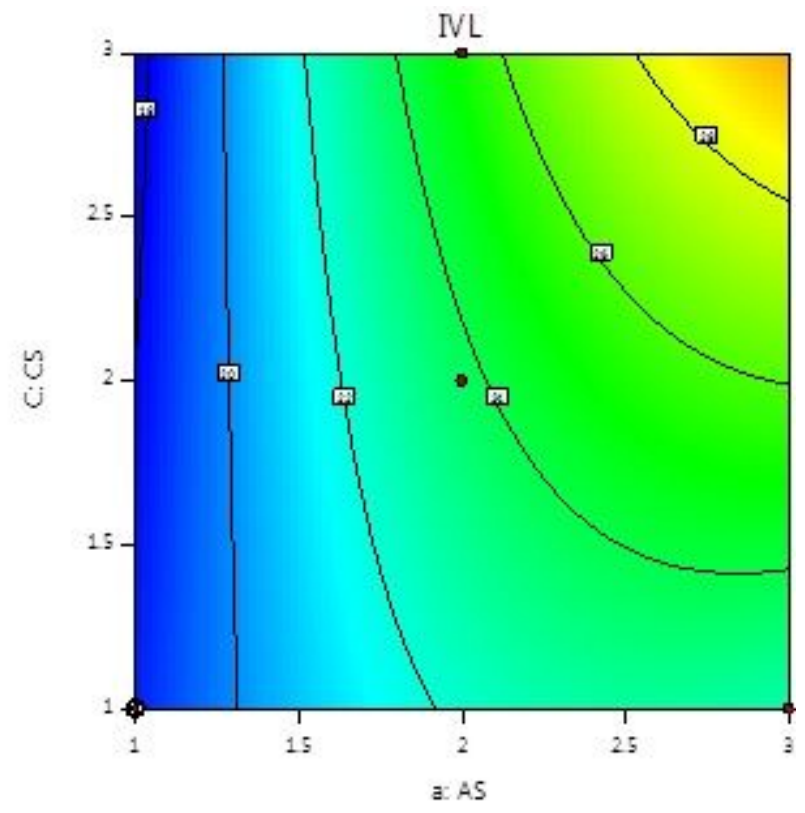

Figure 11

Contour plots for arrangement of spikes $(A S=1)$, concave clearance $(C C=3)$ and cylinder speed $(C S=1)$ with a Invisible loss $=18 \%$ 


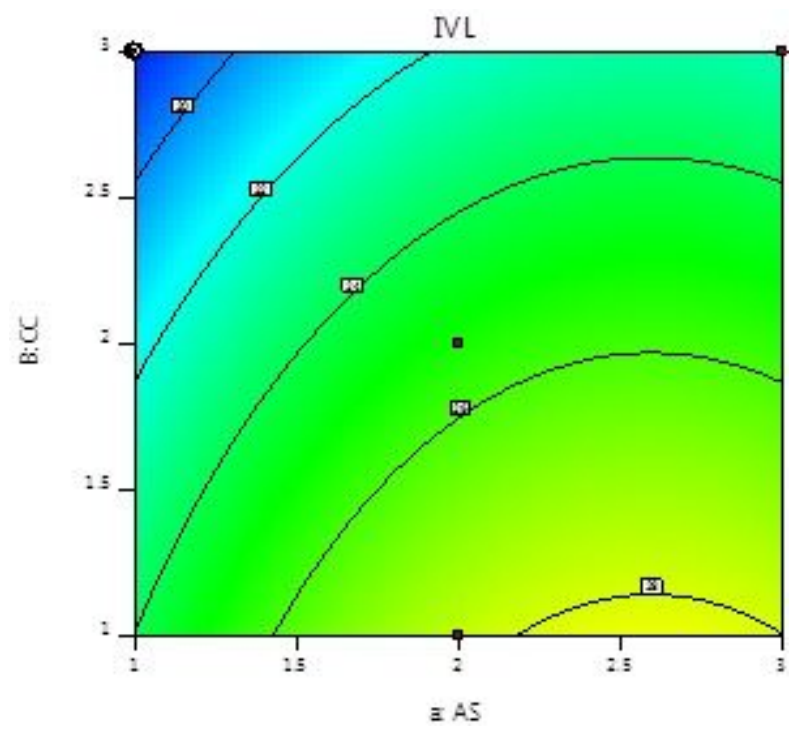

Figure 12

Contour plots for arrangement of spikes $(A S=1)$, concave clearance $(C C=3)$ and cylinder speed $(C S=1)$ with a Invisible loss = $18 \%$

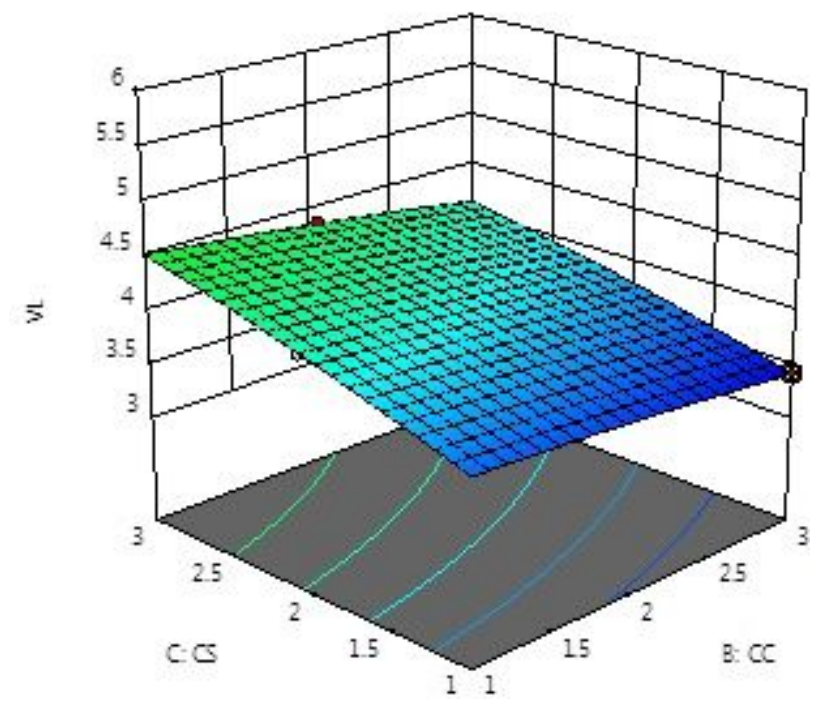

Figure 13

Response surface plots of arrangement of spikes (AS $=1)$, concave clearance $(C C=3)$ and cylinder speed $(C S=1)$ with a Visible loss $=3.42 \%$ 


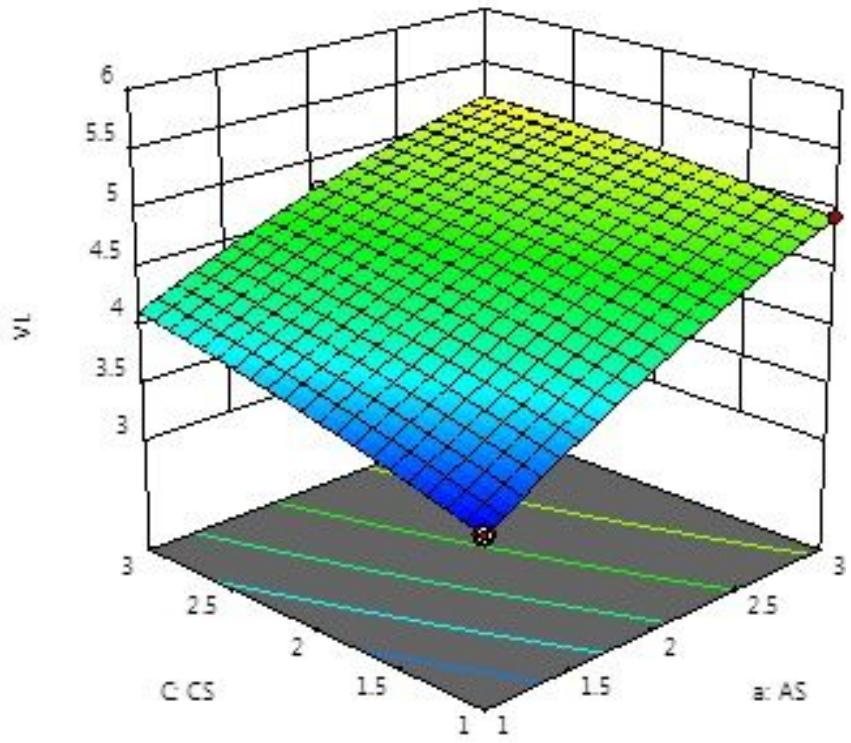

\section{Figure 14}

Response surface plots of arrangement of spikes $(A S=1)$, concave clearance $(C C=3)$ and cylinder speed $(C S=1)$ with a Visible loss $=3.42 \%$

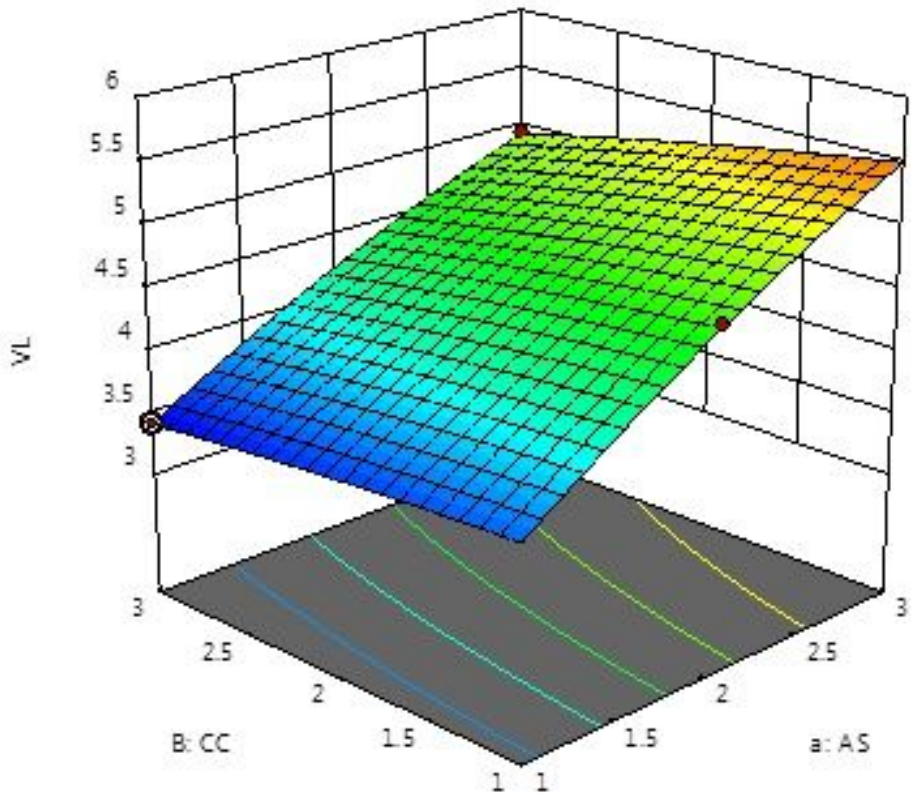

\section{Figure 15}

Response surface plots of arrangement of spikes (AS $=1)$, concave clearance $(C C=3)$ and cylinder speed $(C S=1)$ with a Visible loss $=3.42 \%$ 


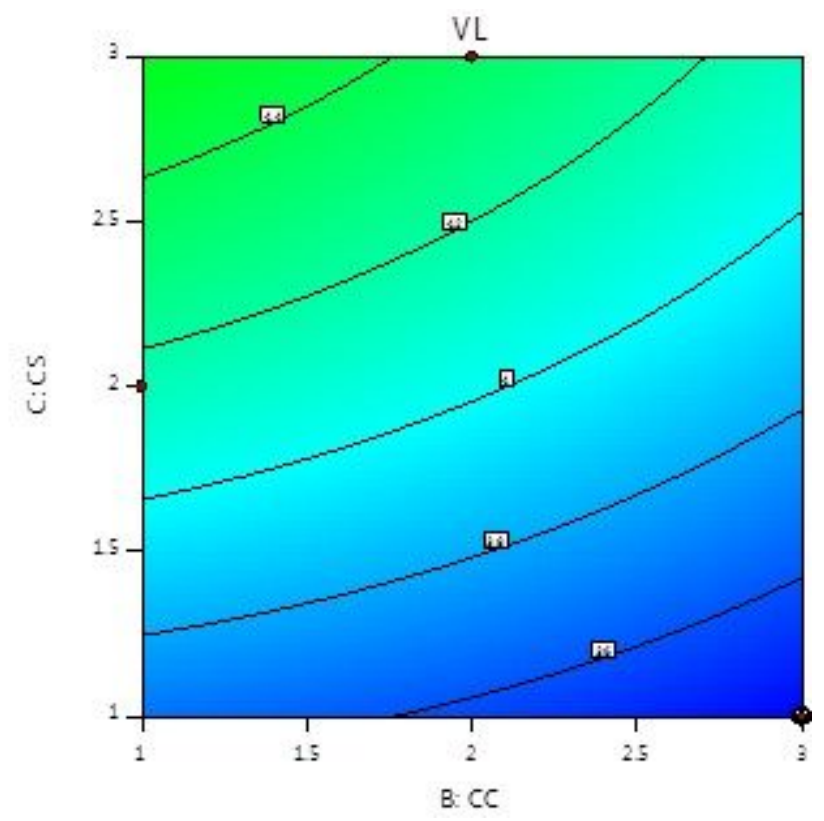

Figure 16

Contour plots of arrangement of spikes $(A S=1)$, concave clearance $(C C=3)$ and cylinder speed $(C S=1)$ with a Visible loss $=3.42 \%$

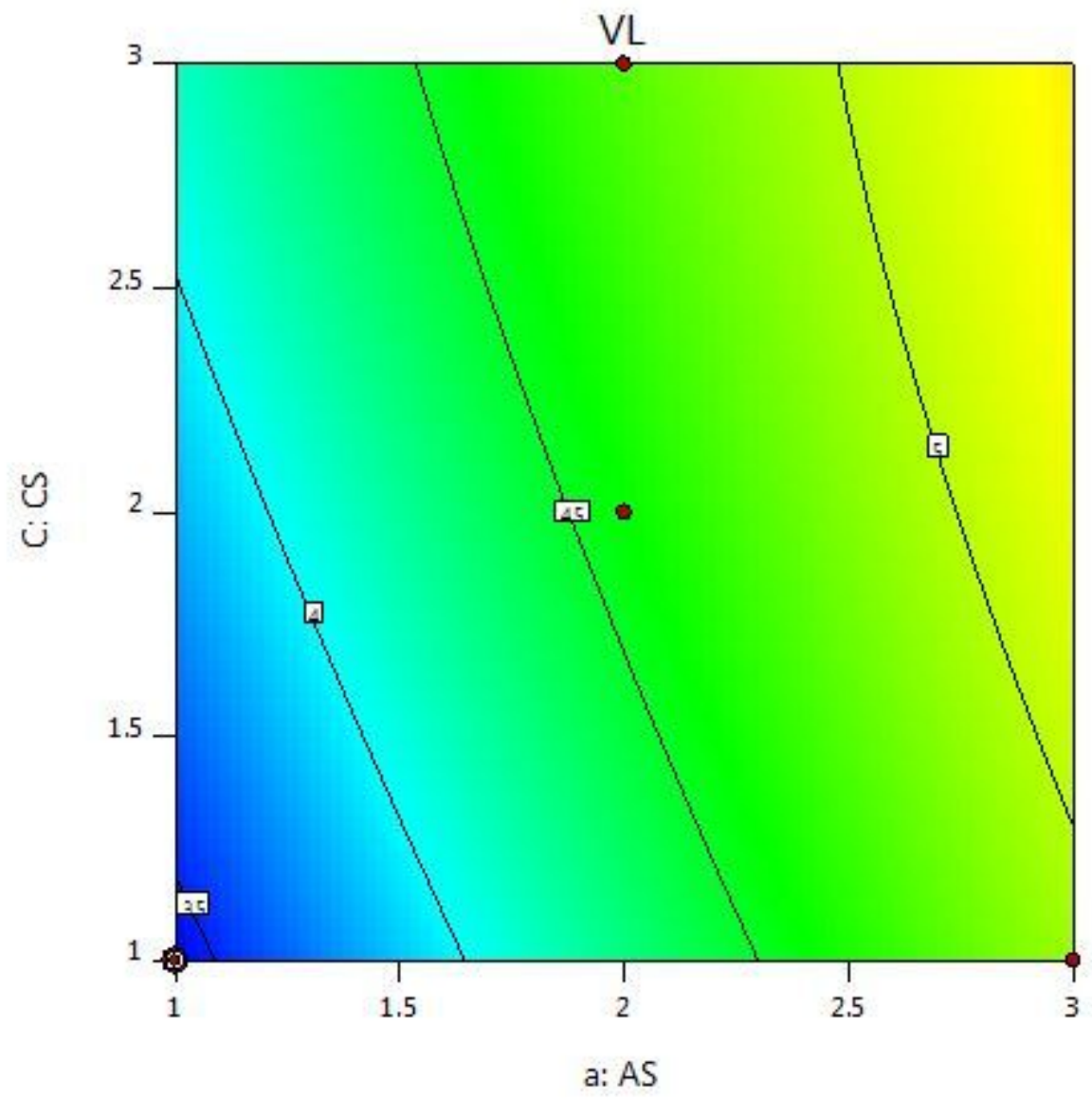

Figure 17 
Contour plots of arrangement of spikes $(A S=1)$, concave clearance $(C C=3)$ and cylinder speed $(C S=1)$ with a Visible loss $=3.42 \%$

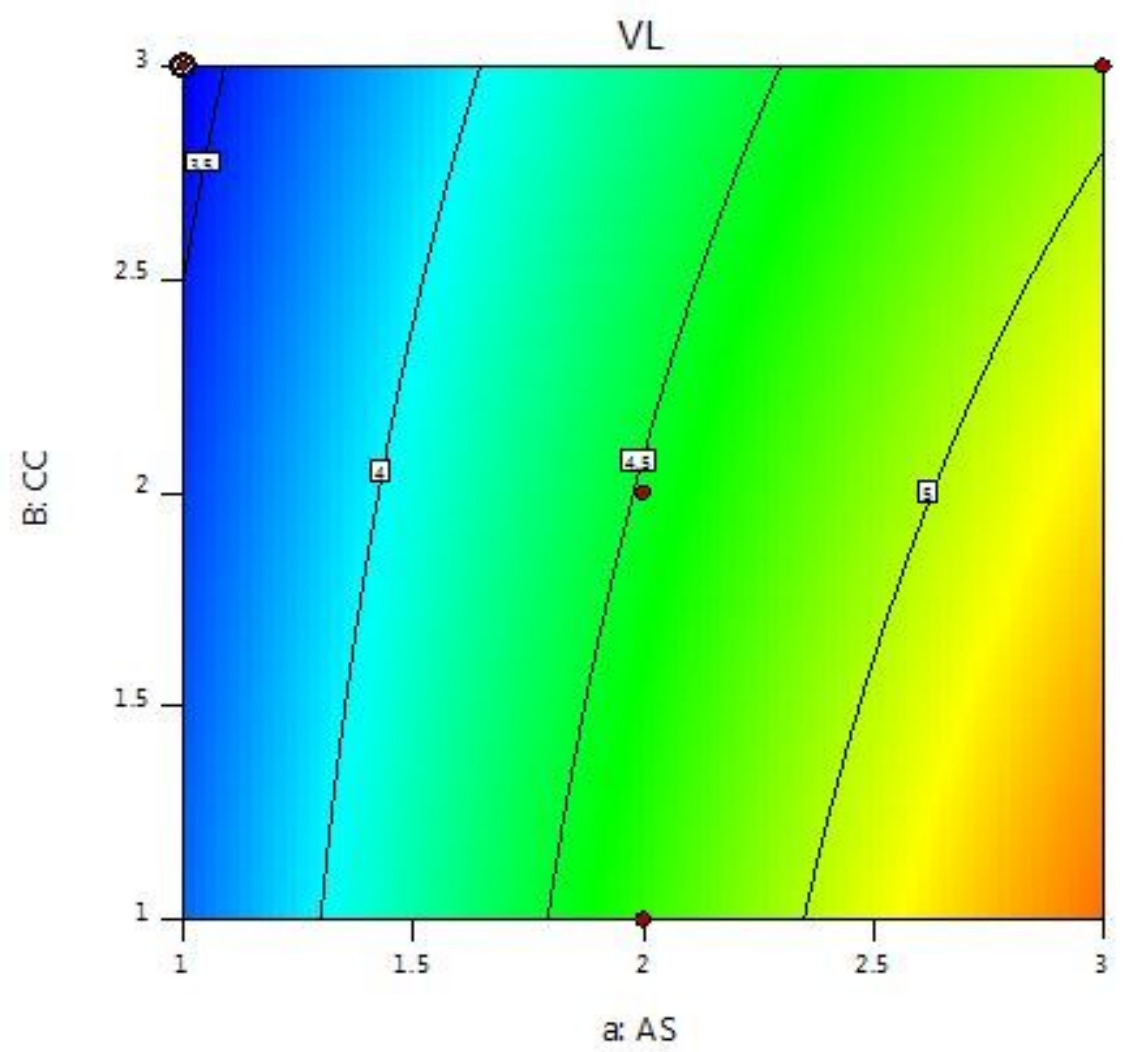

\section{Figure 18}

Contour plots of arrangement of spikes $(A S=1)$, concave clearance $(C C=3)$ and cylinder speed $(C S=1)$ with a Visible loss $=3.42 \%$ 


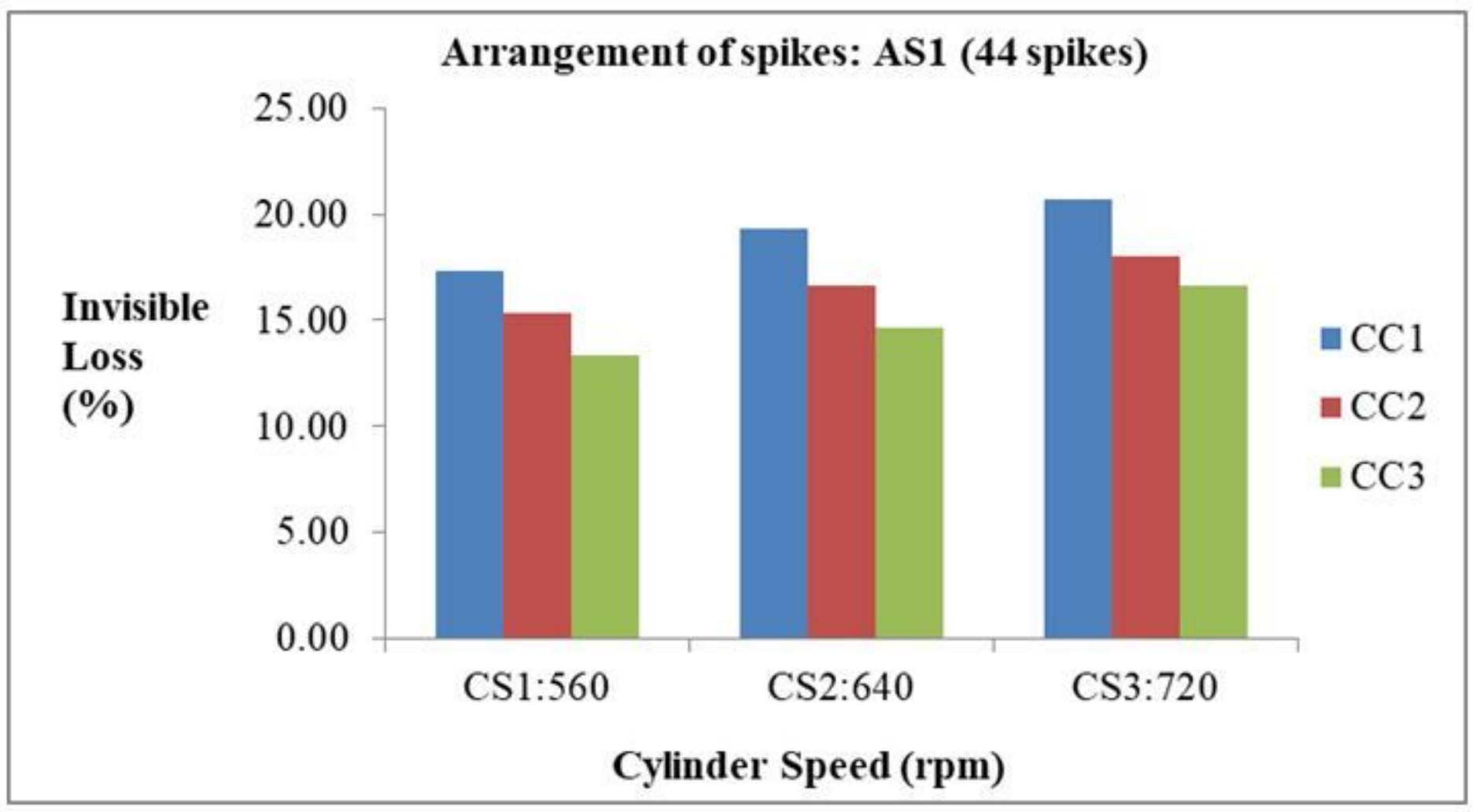

Figure 19

Effect of variation in invisible loss on arrangement of spikes, cylinder speed and concave clearance

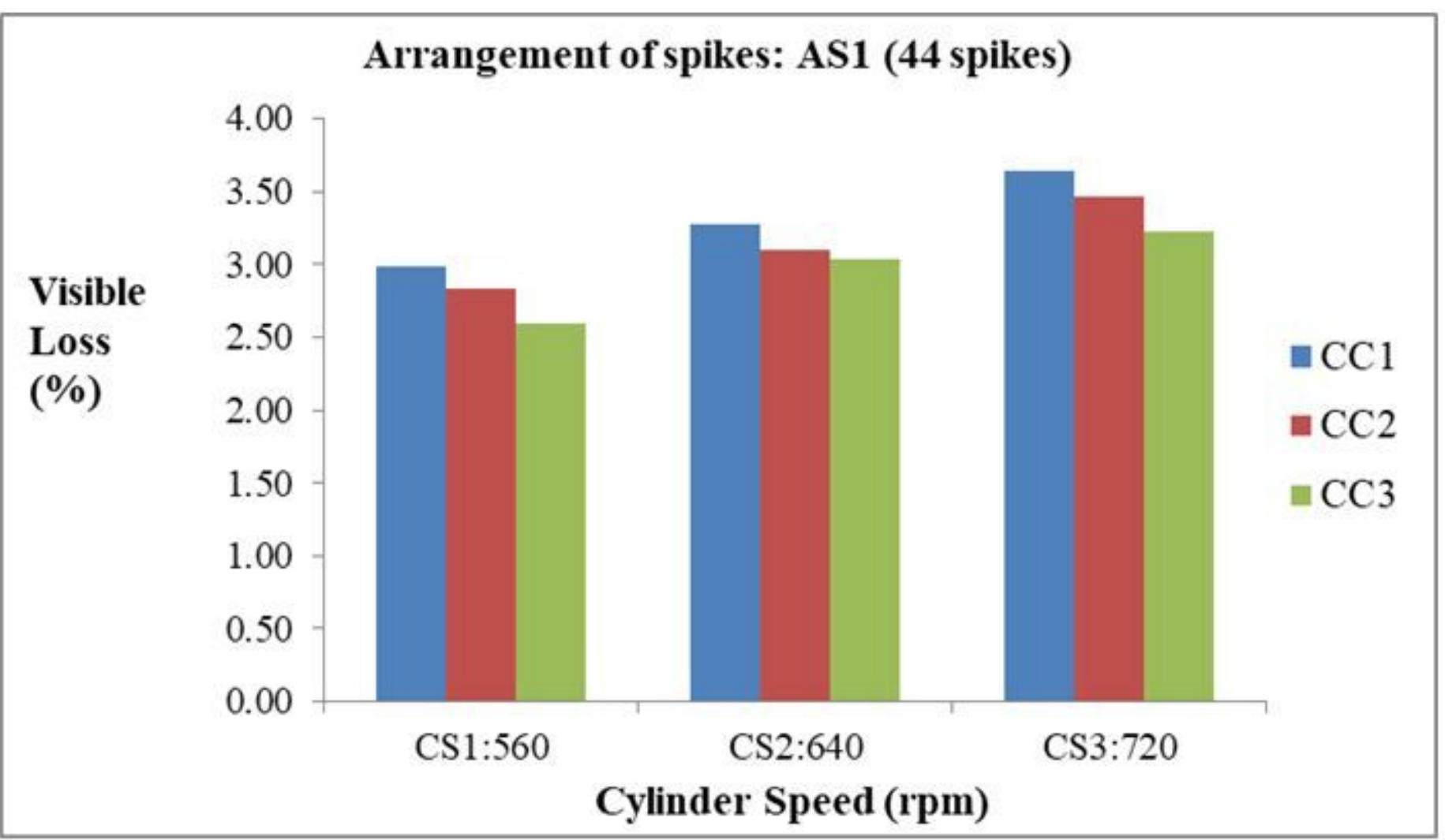

Figure 20 
Effect of variation in invisible loss on arrangement of spikes, cylinder speed and concave clearance

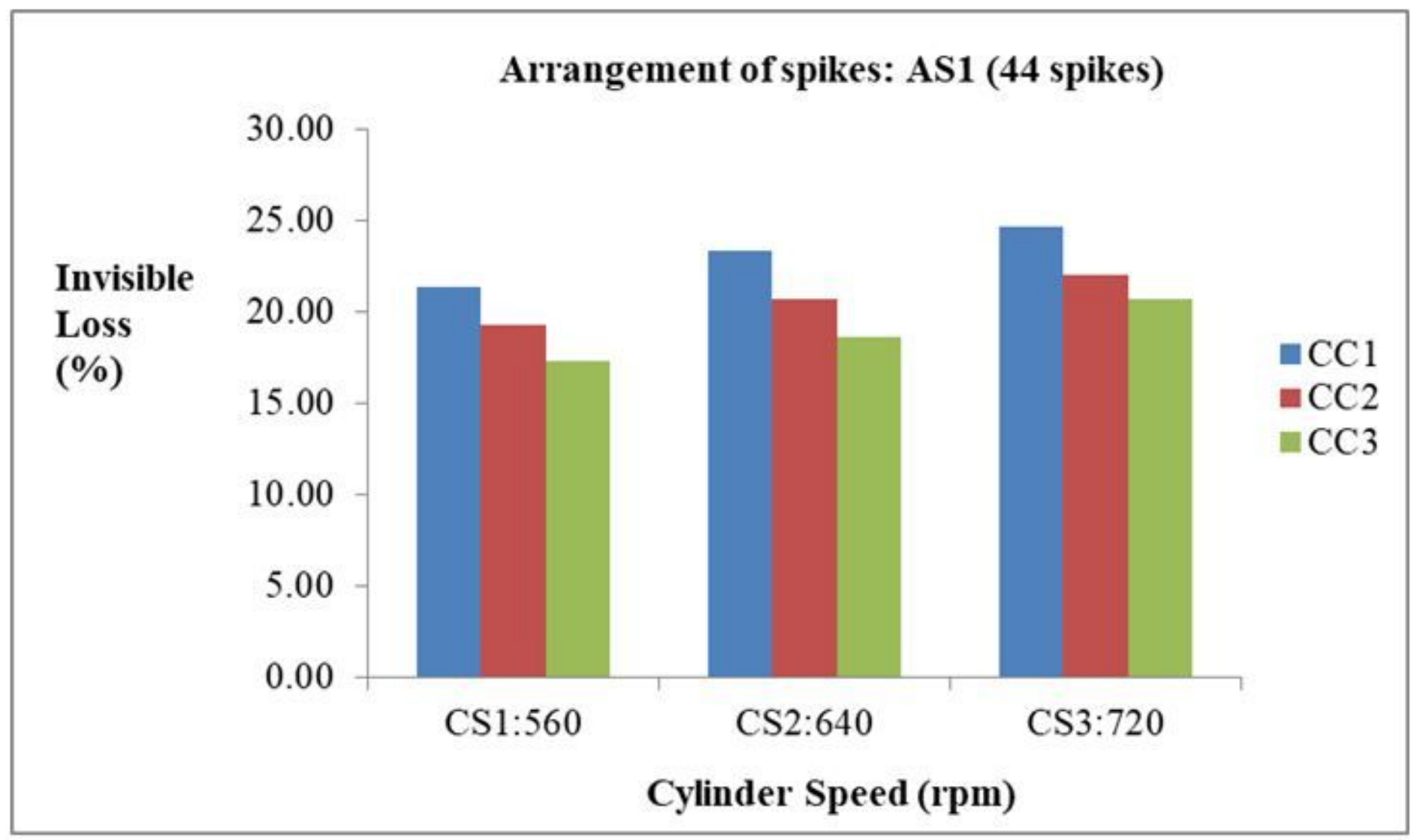

Figure 21

Effect of variation in invisible loss on arrangement of spikes, cylinder speed and concave clearance 


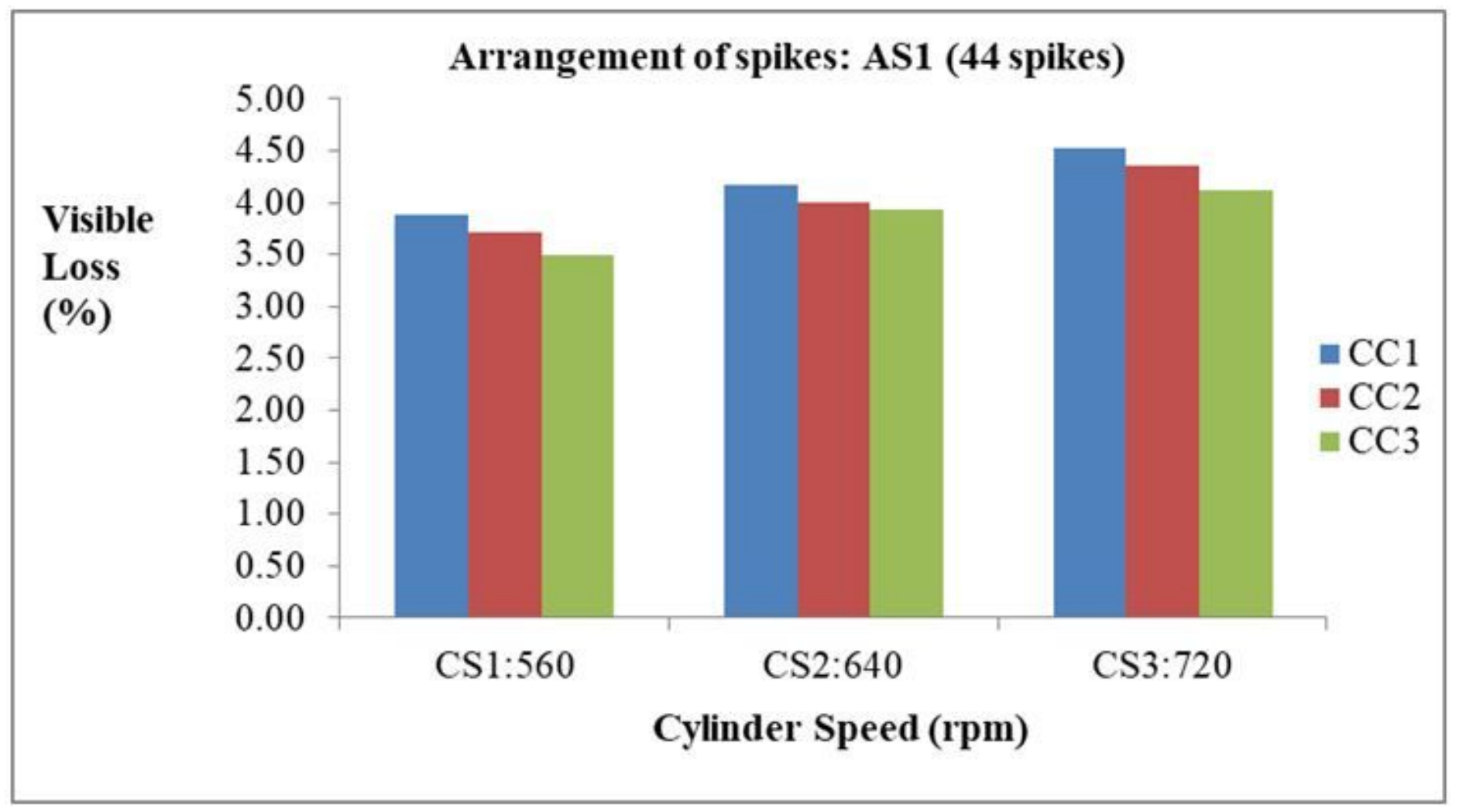

Figure 22

Effect of variation in visible loss on arrangement of spikes, cylinder speed and concave clearance
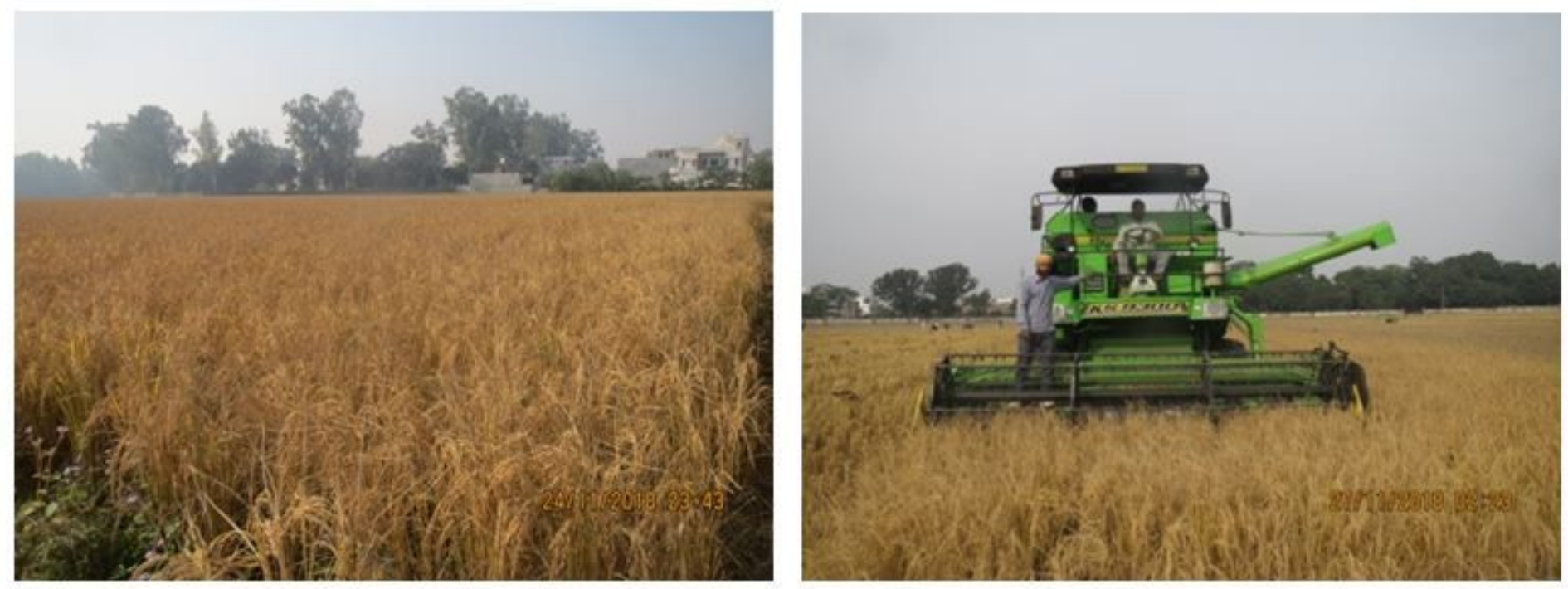

Figure 23

Standing crop of PUSA Basmati- 1121 and conventional combine harvester in operation

\section{Supplementary Files}


This is a list of supplementary files associated with this preprint. Click to download.

- highlights.docx

- highlights.docx

- AUTHORDECLARATION.docx

- AUTHORDECLARATION.docx 